\title{
Extraction Techniques for Isolation, Purification and Preconcentration of Bisphenols and Alkylphenols from Environmental and Food Samples
}

\author{
Malgorzat Mościpan ${ }^{1}$, Piotr P. Wieczorek ${ }^{2, *}$ \\ ${ }^{1}$ Institute of Heavy Organic Synthesis "Blachownia", ul. Energetyków 9, Kędzierzyn-Koźle, Poland, \\ ${ }^{2}$ Opole University, Faculty of Chemistry, Pl. Kopernika 11a, OPOLE (Poland)
}

\begin{abstract}
In this review various methods which are found to apply to the extraction of bisphenols, alkylphenols and their derivatives from solid and liquid samples are presented. Comparison of these techniques in relation to their recovery values, selectivity and the opportunities garnered from applying a phenolic compound in diverse real samples is also discussed. Different extraction methods are presented like ultrasound or microwave assisted extraction, pressurized solvent extraction and matrix solid phase dispersion, as well as solid phase extraction (SPE) including molecularly imprinted polymers as novel and useful sorbents for SPE.
\end{abstract}

\section{INTRODUCTION}

A wide range of chemicals are found in the environment as a consequence of diverse human activity. The presence of various contaminants is related to economic progress, development of industry and agriculture. These substances are present in all areas of the environment and cause adverse effects on the human and animal body, including cancer, disruption of the immune, reproductive and hormone system. These compounds which can influence the functioning of the endocrine system are known as endocrine disrupting compounds (EDCs). They are a large group of chemicals, which either naturally occur or, are synthetic compounds. Due to their structural similarity to endogenous steroid hormones EDCs can bind with suitable receptors and interfere with the functioning of the hormone system. According to the definition presented by the European Commission endocrine disrupting compounds are exogenous substances that alter the function(s) of the endocrine system and consequently cause adverse health effects in an intact organism, or its progeny, or (sub)populations [1]. Moreover most EDCs are persistent and can bio-accumulate along the food chain. One class of EDCs is made up of phenolic compounds which include bisphenols, alkylphenols and various derivatives of these compounds. Both bisphenols and alkylphenols have been shown to possess estrogenic activity in in vitro and in vivo experiments.

Due to the ubiquitous presence of phenolic compounds and their negative influence on the proper development and health necessary to control the concentration of these xenoestrogens in environmental and food samples and develop a reliable method for their determination. Trace amount of analytes and a complexity of samples usually require multi-step preparation techniques and are time- and labour-consuming. Therefore, scientists still search for novel solutions and develop new techniques for simultaneous isolation and preconcentration of analytes and purification of samples during one process. The perfect pretreatment methods should be simple, time saving, inexpensive, efficient, selective and compatible with various determination techniques. For this purpose the most often applied methods are for example solid phase extraction, pressurized solvent extraction and ultrasound or microwave assisted extraction. These methods usually result in the extraction of compounds of interest with satisfactory recovery values, but unfortunately they are not selective enough. It is more and more common to find selective sorbents used in numerous extraction techniques, such as immune-sorbents or molecularly imprinted polymers. The usage of these sorbents can provide an excellent alternative and results in the avoidance of the co-extraction of other substances which are present in the sample.

The main aim of this review is to present various methods which are found to apply to the extraction of bisphenols, alkylphenols and their derivatives from solid and liquid samples and the comparison of 
these techniques in relation to their recovery values, selectivity and the opportunities garnered from applying a phenolic compound in diverse real samples.

\section{Phenolic Compounds}

A wide range of phenolic compounds have been used in various industries, agriculture and in household applications for many years. Phenol is an intermediary for the production of adhesives, phenol-formaldehyde resins, disinfectants, pesticides and dyes. Alkylphenols, their ethoxylates derivatives and chlorophenols are used in the pulp and paper industry (nonylphenols, chlorophenols), during the processing of textiles and leather and in pesticide production (o-phenylphenol). The plastics industry put into use, among others, bisphenol A (BPA) and bisphenol F (BPF) when preparing epoxy resins, polyesters, polyethers and diglycidyl ether of BPA and BPF as a stabilizer of these materials. Halogenated derivatives of phenolic compounds, for example tetrabromobisphenol A is used during the production of flame retardants and pentachlorophenol is suitable for the preservation of wood.

\subsection{Bisphenols}

Bisphenols (BPs) are a group of organic substances which are products of condensation from phenol and ketones or aldehydes. The structure of most of these compounds are based on diphenylmethane and have two hydroxyphenyl functionalities. Bisphenols are used in the plastics industry for the production of polycarbonates, epoxy and phenolic resins, polyethers and polyacrylates. Structures of some bisphenols are presented in Table 1.

Table1.

\begin{tabular}{|l|l|l|l|l|}
\hline $\begin{array}{l}\text { Name } \\
\text { (abbreviation) }\end{array}$ & Systematic name & Structural formula & CAS No. & $\begin{array}{l}\text { Formula } \\
\text { Molecular } \\
\text { weight }\end{array}$ \\
\hline $\begin{array}{l}\text { bisphenol A } \\
\text { (BPA) }\end{array}$ & 2,2 -Bis(4-hydroxyphenyl)propane & $\begin{array}{l}\mathrm{C}_{15} \mathrm{H}_{16} \mathrm{O}_{2} \\
228,3 \mathrm{~g} / \mathrm{mol}\end{array}$ \\
\hline $\begin{array}{l}\text { bisphenol AF } \\
\text { (hexafluoroisopropylidene)diphenol }\end{array}$ & 2,2-Bis(4-hydroxyphenyl)butane & $\begin{array}{l}\text { bisphenol B } \\
\text { bisphenol F } \\
\text { (BPF) }\end{array}$ & bis(4-hydroxyphenyl)methane &
\end{tabular}

Bisphenols are widely used as modifying monomers of plastics which are applied during the production of engineering and composite materials. The most common representative of BPs is bisphenol A (BPA), also referred to as 2,2-bis(4-hydroxyl-phenyl)propane. This substance is a crucial intermediary used for mixing various types of plastic materials and as a stabilizer and an antioxidant in some polymers, for example polyvinylchloride. This synthetic compound is suitably used in a large number of consumer products like packaging for foods and beverages, baby bottles, carpets, medical equipment, electronic devices, coatings, automotive parts, dental fillings and a lot of other applications [2, 3].

Although bisphenol A has been successfully used for many years in industry for the preparation of sundry products, the result of numerous research obtained over the past twenty years clearly 
demonstrates that this substance is a ubiquitous contaminator and indicates biological activity in trace concentration. BPA enters the environment and food mainly from these plastic material which contain this substance. Due to fact that the majority of the polymerization process does not precede a yield of $100 \%$, final products may contain trace amounts of unreacted substrates. Subsequently these residues may be released into the environment. Heating, salinity, presence of acid or its foundations increases the rate of the hydrolysis reaction. The period of time of food storage in containers made of plastic materials is also a significant factor. The presence of bisphenols (BPs) and biphenyl were observed in food simulates after 10 day of storage in cans at $40^{\circ} \mathrm{C}$. The concentration of analytes were in the range of $0.04-0.35 \mu \mathrm{g} / \mathrm{L}$. The authors also identified these xenobiotics in some canned food and beverage samples. BPs were detected in the most samples at the concentration levels in the range of 0.08-13.98 $\mu \mathrm{g} / \mathrm{L}$, whereas biphenyl was found only in one sample [4]. BPA, BPF, bisphenol A diglycidyl ether (BADGE) and bisphenol F diglycidyl ether (BFDGE) were found in food simulates. The migrating levels of bisphenol A and BADGE found in various can samples were in the range of $0.63 \mu \mathrm{g} / \mathrm{L}$ to $340 \mu \mathrm{g} / \mathrm{L}$ and from $1.49 \mu \mathrm{g} / \mathrm{L}$ to $3670 \mu \mathrm{g} / \mathrm{L}$, respectively, whereas BPF and BFDGE were not practically detected [5].

European Legislation set a specific migration limit (SML) of bisphenol A to food products at the level of $0.6 \mathrm{mg} / \mathrm{kg}$. Both, European Commission and US Environmental Protection Agency, established tolerable daily intake (TDI) and reference doses of bisphenol A as $0.05 \mathrm{mg} /$ body weight/day [6]. In addition, the European Union banned the production of baby bottles containing BPA from March 2011 and those imported into member states since June 2011. Furthermore European Legislation established that sum of migration limit of BADGE, BFDGE and their chlorohydroxy and hydrolysis derivatives should not exceed the concentration of $1 \mathrm{mg} / \mathrm{kg}$ in foodstuff [7].

Bisphenol $\mathrm{A}$ is a known endocrine disrupting compound and can negatively affect the health of a living organism. Endocrine activity of BPA was known from the 1930s. At the time these properties were used in husbandry for the fostering and growth of animals. BPA was also found to be suitable during hormone therapy before it was replaced by diethylstilbestrol $[8,9]$. Bisphenol A can bind with estrogen receptors and unsettle the proper functioning of the endocrine system. The affinity of this compound for ER- $\alpha$ and ER- $\beta$ is about 10 thousand times weaker than 17- $\beta$-estradiol [10], therefore it is a weak xenoestrogen. Moreover it can also demonstrate antiandrogenic activity [11]. Other bisphenols: bisphenol $\mathrm{F}$, bisphenol $\mathrm{E}$ and bisphenol $\mathrm{B}$ have similar estrogenic activity as BPA, whereas bisphenol $\mathrm{S}$ shows higher biological activity, probably due to its polarity. These substances show agonistic effects [12]. Numerous references clearly indicate that bisphenols are harmful and can affect the functionality of the hormone system in low concentrations. These compounds have a broad spectrum of activity and may cause structural and neurochemical changes in the brain closely connected with hyperactivity, learning difficulties and memorizing aggression. Other disorders are infertility, advanced puberty, endometriosis, thyroid diseases and cancer [8,9].

\subsection{Alkylphenols}

Polyethoxylate alkylphenols (APEs) are a large group of surfactants which are used in industry, agriculture and the household. They are found in applications such as detergents, emulsifiers, wetting, dispersing and blowing agents. These compounds were applied in various type of industry, for example plastics, textile, pulp and paper industry. Amongst these substances one of the most frequently used is polyethoxylated nonylphenol which is produced to amounts of 400 thousand tons a year due to its broad spectrum of uses. Nonylphenol (NP) is an organic substance commonly used for the production of antioxidants (10\%), additives for gear oil (18\%) and surfactants (65\%). NP and octylphenol are intermediaries needed to produce anionic and non-ion surfactants and may also be used as stabilizers of phenol resins and ethylcellulose resins [13].

These compounds are released mainly into the aquatic environment with industrial and municipal sludge and runoff from agricultural fields due to the use of pesticides. A significant source of human exposure to alkylphenolic xenobiotics is also food. The content of NP and its polyethoxylates derivatives in surface water samples (Spain) were set by the authors at a level of $343 \mu \mathrm{g} / \mathrm{L}$ and 938 $\mu \mathrm{g} / \mathrm{L}$, respectively [14]. NP, octylphenol and polyethoxylated nonylphenol (NPE) were detected in wastewater effluents (USA). Concentrations of NP and OP ranged from less than the method detection limit to 37 and $0.7 \mu \mathrm{g} / \mathrm{L}$, whereas the concentration of NPE was meaningfully higher and ranged from less than the MDL to $332 \mu \mathrm{g} / \mathrm{L} \mathrm{[15].} \mathrm{Nonylphenol} \mathrm{was} \mathrm{also} \mathrm{measured} \mathrm{in} \mathrm{the} \mathrm{air} \mathrm{in}$ amounts of 2.2-70 ng/ $\mathrm{m}^{3}$ [16]. The presence of alkylphenols and ethoxylated alkylphenols was 
describe in tissues and body fluids of living organisms, for example human breast milk revealed NP, octylphenol, mono- and diethoxylated octylphenol at a concentration level of 13.4-56.3 ng/ml, > 21 $\mathrm{ng} / \mathrm{ml}, 0.05-0.1 \mathrm{ng} / \mathrm{ml}$ and $0.11-0.27 \mathrm{ng} / \mathrm{ml}$, respectively [17].

Degradation of APEs in the environment generates a formation of more stable mono-, di- and triethoxylated alkylphenols, alkylphenoxyacetic acid and alkylphenols. All these compounds, like bisphenols, exhibit endocrine activity and can imitate natural hormones. Nonylphenol and octylphenol are able to bind with estrogen receptors and modify the action of endogenous steroid hormones. The affinity of these two substances to estrogen receptors is from a few thousand to tens of thousands of times weaker than $17 \beta$-estradiol [18]. In addition some alkylphenolic compounds also show antiandrogenic activity [11]. Biological activity demonstrates only these APEs which have a short polyethoxylated chain (three or less atoms of carbon) connected to a phenolic ring and a long hydrocarbon chain (tree or more carbon atoms). Furthermore much stronger xenoestrogens are generally 'para' isomers $[18,19]$.

\section{EXTRACTION METHODS OF BISPHENOLS AND ALKYLPHENOLS FROM ENVIRONMENTAL AND FOOD SAMPLES}

Due to the ubiquitous presence of bisphenols, alkylphenols and their derivatives in surface water, groundwater, soil, air and food and their adverse effect on living organisms it is necessary to systematically control the concentration of phenolic compounds in various elements of the environment. The second crucial aspect is to develop reliable and meaningful methods enabling isolation, preconcentration and determination through these groups of xenoestrogens from complex samples like environmental samples and food.

The clarification of trace amounts of compounds usually requires time- and labour-consuming techniques for preparation samples which include separation, preconcentration and purification steps of analytes. For this purpose the most often used methods are liquid-liquid extraction [20-22], Soxhlet extraction [3, 23], solid phase extraction [6, 22, 24-44], membrane extraction [45-47], accelerated solvent extraction [7, 13, 48-54], ultrasonic assisted extraction [32, 55-58], microwave assisted extraction [59-61], stir-bar sorptive extraction [4, 62-69], matrix solid phase dispersion [70-74] or dispersive liquid-liquid microextraction [75-81].

When examining this group of analytes the techniques which are commonly used are: high performance liquid chromatography coupled with spectrophotometric detector [36, 38, 41, 43, 77, 82] or fluorescence detector $[22,31,40-42,56,59,67-69,72,78,79]$, liquid chromatography coupled with mass spectrometry $[3,6,7,13,24-26,28,30,39,44,48,49,60,73-75]$, gas chromatography coupled with mass spectrometry $[5,20,21,23,27,29,51,52,57,58,61-66,70,76,80]$ or capillary electrophoresis [37].

Examples of methods applying for extraction of bisphenols and alkylphenols from environmental and food samples are presented in detail in Table 2.

Table2.

\begin{tabular}{|l|l|l|l|l|l|l|l|}
\hline Analyte & Sample & Extraction & Detection & $\begin{array}{l}\text { Recovery, } \\
\%\end{array}$ & Concentration & LOD & Reference \\
\hline $\begin{array}{l}\text { bisphenol A } \\
\text { mono- di- tri- and } \\
\text { tetrabromobisphenol } \\
\text { A } \\
\text { tetrachlorobisphenol } \\
\text { A }\end{array}$ & $\begin{array}{l}\text { sediment } \\
\text { sludge }\end{array}$ & $\begin{array}{l}\text { Soxhlet } \\
\text { extraction/SPE }\end{array}$ & LC-MS & $70-105$ & $0.1-74.38 \mathrm{ng} / \mathrm{g}$ & $\begin{array}{l}\text { LOQ: } \\
0.02-0.15 \\
\mathrm{ng} / \mathrm{g}\end{array}$ & {$[3]$} \\
\hline $\begin{array}{l}\text { bisphenol A } \\
\text { bisphenol F } \\
\text { and their diglycidyl } \\
\text { ethers }\end{array}$ & wastewater & LLE & GC-MS & no data & $\begin{array}{l}60-50000 \\
\text { ng/L }\end{array}$ & $\begin{array}{l}6-130 \\
\mathrm{ng} / \mathrm{L}\end{array}$ & {$[20]$} \\
\hline $\begin{array}{l}\text { bisphenol A } \\
\text { 4-tert-octylphenol } \\
\text { 4-nonylphenol }\end{array}$ & river water & LLE & GC-MS & $80-11 \%$ & $18-8300 \mathrm{ng} / \mathrm{L}$ & $\begin{array}{l}0.17-0.73 \\
\mathrm{ng} / \mathrm{L}\end{array}$ & {$[21]$} \\
\hline $\begin{array}{l}\text { bisphenol A } \\
\text { bisphenol B } \\
\text { bisphenol E } \\
\text { bisphenol F } \\
\text { bisphenol S }\end{array}$ & $\begin{array}{l}\text { canned soft } \\
\text { drinks }\end{array}$ & on-line SPE & $\begin{array}{l}\text { LC- } \\
\text { MS/MS }\end{array}$ & $85-100$ & $\begin{array}{l}>\text { LOD-607 } \\
\text { ng/L }\end{array}$ & $5-50 \mathrm{ng} / \mathrm{L}$ & {$[6]$} \\
\hline
\end{tabular}


Extraction Techniques for Isolation, Purification and Preconcentration of Bisphenols and Alkylphenols from Environmental and Food Samples

\begin{tabular}{|c|c|c|c|c|c|c|c|}
\hline $\begin{array}{l}\text { bisphenol A } \\
\text { and its chlorinated } \\
\text { derivatives }\end{array}$ & $\begin{array}{l}\text { river water } \\
\text { wastewater } \\
\text { drinking } \\
\text { water } \\
\text { treatment } \\
\text { plant }\end{array}$ & on-line SPE & $\begin{array}{l}\mathrm{LC}- \\
\mathrm{MS} / \mathrm{MS}\end{array}$ & $85-100$ & $101-836 \mathrm{ng} / \mathrm{L}$ & $\begin{array}{l}\text { LOQ: } \\
57-183 \\
n g / L\end{array}$ & {$[25]$} \\
\hline $\begin{array}{l}\text { bisphenol A } \\
\text { tetrabromobisphenol } \\
\text { A }\end{array}$ & wastewater & off-line SPE & $\begin{array}{l}\mathrm{LC}- \\
\mathrm{MS} / \mathrm{MS}\end{array}$ & $81-120$ & $13-31.9 \mathrm{ng} / \mathrm{L}$ & $\begin{array}{l}10-20 \\
\mathrm{ng} / \mathrm{L}\end{array}$ & {$[24]$} \\
\hline $\begin{array}{l}\text { bisphenol A } \\
\text { phenylphenol } \\
\text { alkylphenolic } \\
\text { compounds } \\
\text { parabens } \\
\end{array}$ & $\begin{array}{l}\text { surface } \\
\text { water (sea, } \\
\text { river, } \\
\text { lagoon) } \\
\text { wastewater } \\
\end{array}$ & off-line SPE & $\begin{array}{l}\mathrm{LC}- \\
\mathrm{MS} / \mathrm{MS}\end{array}$ & $91-124$ & $\begin{array}{l}>\mathrm{LOQ}-6150 \\
\mathrm{ng} / \mathrm{L}\end{array}$ & $\begin{array}{l}\text { LOQ: } \\
0.2-29 \\
\text { ng/L }\end{array}$ & {$[28]$} \\
\hline bisphenol A & \begin{tabular}{|l|} 
milk \\
powdered \\
infant \\
formula \\
\end{tabular} & off-line SPE & LC-MS & $83-106$ & $\begin{array}{l}<\mathrm{LOD}-15.2 \\
\mathrm{ng} / \mathrm{L}\end{array}$ & $1.7 \mathrm{ng} / \mathrm{g}$ & {$[30]$} \\
\hline $\begin{array}{l}\text { BADGE } \\
\text { BFDGE } \\
\text { and their derivatives }\end{array}$ & $\begin{array}{l}\text { canned } \\
\text { beverages }\end{array}$ & off-line SPE & $\begin{array}{l}\mathrm{LC}- \\
\mathrm{MS} / \mathrm{MS}\end{array}$ & $70-95$ & $\begin{array}{l}2100-5100 \\
\mathrm{ng} / \mathrm{kg}\end{array}$ & $\begin{array}{l}\text { LOQ; } \\
130-1600 \\
\text { ng/L } \\
\end{array}$ & {$[32]$} \\
\hline $\begin{array}{l}\text { bisphenol A } \\
\text { bisphenol F }\end{array}$ & honey & off-line SPE & $\begin{array}{l}\text { LC-FL } \\
\text { LC-MS }\end{array}$ & $95-104$ & $>$ LOD-33.3 & no data & {$[33]$} \\
\hline bisphenol A & $\begin{array}{l}\text { chemical } \\
\text { cleansing } \\
\text { cosmetics } \\
\end{array}$ & MI-SPE & $\begin{array}{l}\text { HPLC- } \\
\text { FLD }\end{array}$ & $89-97$ & $\begin{array}{l}1.46-2.69 \\
\mathrm{nmol} / \mathrm{g}\end{array}$ & $\begin{array}{l}0.001 \\
\mu \mathrm{mol} / \mathrm{L}\end{array}$ & {$[41]$} \\
\hline bisphenol A & river water & MI-SPE & LC-MS & 99 & $32 \mathrm{ng} / \mathrm{L}$ & $1 \mathrm{ppt}$ & {$[44]$} \\
\hline bisphenol A & $\begin{array}{l}\text { tap water } \\
\text { river water } \\
\text { municipal } \\
\text { sewage } \\
\text { effluent }\end{array}$ & CFLME & $\begin{array}{l}\text { HPLC- } \\
\text { DAD }\end{array}$ & $76-116$ & $280 \mathrm{ng} / \mathrm{L}$ & $30 \mathrm{ng} / \mathrm{L}$ & {$[46]$} \\
\hline $\begin{array}{l}\text { bisphenol A } \\
\text { octylphenol } \\
\text { nonylphenol }\end{array}$ & $\begin{array}{l}\text { food } \\
\text { (various } \\
\text { kind of } \\
\text { meat) }\end{array}$ & PLE/SPE & $\begin{array}{l}\mathrm{LC}- \\
\mathrm{MS} / \mathrm{MS}\end{array}$ & 89-103 & $80-55980 \mathrm{ng} / \mathrm{g}$ & $\begin{array}{l}50-300 \\
\mathrm{ng} / \mathrm{g}\end{array}$ & {$[13]$} \\
\hline $\begin{array}{l}\text { bisphenol A } \\
\text { octylphenol } \\
\text { nonylphenol }\end{array}$ & $\begin{array}{l}\text { food } \\
\text { (powdered } \\
\text { milk, infant } \\
\text { formulas) }\end{array}$ & PLE & $\begin{array}{l}\text { LC- } \\
\text { MS/MS }\end{array}$ & 89-101 & $26-1550 \mathrm{ng} / \mathrm{g}$ & $3-5 \mathrm{ng} / \mathrm{g}$ & {$[48]$} \\
\hline $\begin{array}{l}\text { bisphenol A } \\
\text { estrogens (E1, E2, } \\
\text { EE2, E3) }\end{array}$ & soil & PLE & GC-MS & 71-118 & $\begin{array}{l}>\text { LOD-67.3 } \\
\mathrm{ng} / \mathrm{g}\end{array}$ & $\begin{array}{l}0.02-0.37 \\
\mathrm{ng} / \mathrm{g}\end{array}$ & {$[52]$} \\
\hline \begin{tabular}{|l|} 
bisphenol A \\
tetrabromobisphenol \\
A \\
tetrachlorobisphenol
\end{tabular} & soil & SAESC & GC-MS & 88-108 & $0,2-44.5 \mathrm{ng} / \mathrm{g}$ & $\begin{array}{l}0.03-0.09 \\
\mathrm{ng} / \mathrm{g}\end{array}$ & {$[55]$} \\
\hline $\begin{array}{l}\text { bisphenol A } \\
\text { diglicydyl ether and } \\
\text { its derivatives } \\
\text { Novolac glycidyl } \\
\text { ethers }\end{array}$ & $\begin{array}{l}\text { food (fish, } \\
\text { meat) }\end{array}$ & MAE/SPE & $\begin{array}{l}\text { HPLC- } \\
\text { FLD }\end{array}$ & 71-104 & $\begin{array}{l}>\text { LOD-173.4 } \\
\mathrm{ng} / \mathrm{g}\end{array}$ & $\begin{array}{l}0.79-3.77 \\
\mathrm{ng} / \mathrm{g}\end{array}$ & [59] \\
\hline $\begin{array}{l}\text { bisphenol A } \\
\text { 4-tert-octylphenol } \\
\text { 4-nonylphenol } \\
\text { estrogens }\end{array}$ & $\begin{array}{l}\text { river } \\
\text { sediments }\end{array}$ & MAE & GC-MS & $74-96$ & $\begin{array}{l}\text { >LOD-12 } \\
\text { ng/g r.m. }\end{array}$ & $\begin{array}{l}0.2-1.0 \\
\mathrm{ng} / \mathrm{g} \mathrm{r.m} .\end{array}$ & {$[61]$} \\
\hline $\begin{array}{l}\text { bisphenol A } \\
\text { bisphenol Z } \\
\text { bisphenol Z } \\
\text { biphenol }\end{array}$ & $\begin{array}{l}\text { canned } \\
\text { beverages } \\
\text { and filling } \\
\text { liquids of } \\
\text { canned food }\end{array}$ & SBSE & GC-MS & $86-122$ & $\begin{array}{l}80-13980 \\
n g / L\end{array}$ & $0.9-2.5$ & {$[4]$} \\
\hline
\end{tabular}


Malgorzat Mościpan \& Piotr P. Wieczorek

\begin{tabular}{|c|c|c|c|c|c|c|c|}
\hline $\begin{array}{l}\text { bisphenol A } \\
\text { 4-tert-octylphenol } \\
\text { nonylphenol }\end{array}$ & river water & SBSE & GC-MS & $85-106$ & $2.5-14.9 \mathrm{ng} / \mathrm{L}$ & $\begin{array}{l}0.1-3.2 \\
\mathrm{ng} / \mathrm{L}\end{array}$ & [62] \\
\hline bisphenol A & $\begin{array}{l}\text { river water } \\
\text { body fluids }\end{array}$ & SBSE & GC-MS & $95-105$ & $39-450 \mathrm{ng} / \mathrm{L}$ & $\begin{array}{l}1-100 \\
\mathrm{ng} / \mathrm{L}\end{array}$ & [63] \\
\hline \begin{tabular}{|l|} 
bisphenol A \\
alkylphenols \\
hormones \\
sterols
\end{tabular} & $\begin{array}{l}\text { estuarine } \\
\text { water } \\
\text { wastewater }\end{array}$ & UAE/SBSE & GC-MS & 78-124 & $\begin{array}{l}<\text { LOD-608 } \\
\text { ng/L }\end{array}$ & $\begin{array}{l}0.8-84 \\
\mathrm{ng} / \mathrm{L}\end{array}$ & [64] \\
\hline $\begin{array}{l}\text { bisphenol A } \\
\text { 4-tert-octylphenol } \\
\text { 4-nonylphenol } \\
\text { chlorophenols }\end{array}$ & $\begin{array}{l}\text { soil } \\
\text { sediment }\end{array}$ & UAE/SBSE & GC-MS & $70-89$ & $10-901 \mathrm{ng} / \mathrm{g}$ & $\begin{array}{l}0.2-1.7 \\
\mathrm{ng} / \mathrm{g}\end{array}$ & [66] \\
\hline bisphenol A & milk & SBSE & $\begin{array}{l}\text { HPLC- } \\
\text { FLD }\end{array}$ & 89.5-108 & $160-360 \mathrm{ng} / \mathrm{L}$ & $6.84 \mathrm{ng} / \mathrm{L}$ & [67] \\
\hline bisphenol A & tap water & SBSE & $\begin{array}{l}\text { HPLC- } \\
\text { FLD }\end{array}$ & 88 & $47.5 \mathrm{ng} / \mathrm{L}$ & $5.7 \mathrm{ng} / \mathrm{L}$ & [68] \\
\hline bisphenol A & \begin{tabular}{|l} 
drinking \\
water \\
leachate of \\
on-off \\
dishware
\end{tabular} & SBSE & $\begin{array}{l}\text { HPLC- } \\
\text { FLD }\end{array}$ & $86-116$ & $100-470 \mathrm{ng} / \mathrm{L}$ & $8 \mathrm{ng} / \mathrm{L}$ & [69] \\
\hline nonylphenol & soil & MSPD & GC-MS & 100-105 & $0.45 \mathrm{ng} / \mathrm{g}$ & $0.1 \mathrm{ng} / \mathrm{g}$ & [70] \\
\hline $\begin{array}{l}\text { bisphenol A } \\
\text { estrogens }\end{array}$ & $\begin{array}{l}\text { food (milk, } \\
\text { meat) }\end{array}$ & MSPD & $\begin{array}{l}\text { UPLC- } \\
\text { MS }\end{array}$ & $60-128$ & $0.13-1.71$ & $\begin{array}{l}110-810 \\
\mathrm{ng} / \mathrm{L}\end{array}$ & [71] \\
\hline $\begin{array}{l}\text { bisphenol A } \\
\text { estrogens }\end{array}$ & \begin{tabular}{|l} 
sediment \\
tissue
\end{tabular} & MSPD & $\begin{array}{l}\text { UPLC- } \\
\text { MS }\end{array}$ & $30-111$ & $\begin{array}{l}<\text { LOD-287 } \\
\mathrm{ng} / \mathrm{g}\end{array}$ & $\begin{array}{l}0.05-19.8 \\
\mathrm{ng} / \mathrm{L}\end{array}$ & [73] \\
\hline $\begin{array}{l}\text { bisphenol A } \\
\text { octylphenol } \\
\text { nonylphenol }\end{array}$ & $\begin{array}{l}\text { food (eggs, } \\
\text { milk) }\end{array}$ & MSPD & LC-MS & 79-98 & $0.1-7.6 \mathrm{ng} / \mathrm{g}$ & $\begin{array}{l}0.05-0.25 \\
\mathrm{ng} / \mathrm{g}\end{array}$ & [74] \\
\hline $\begin{array}{l}\text { 4-tert-octylphenol } \\
\text { 4-octylphenol } \\
\text { 4-n-nonylphenol } \\
\text { nonylphenol } \\
\text { bisphenol A }\end{array}$ & seawater & DLLME & $\begin{array}{l}\text { LC- } \\
\text { MS/MS }\end{array}$ & 84-104 & $\begin{array}{l}<\mathrm{MQL}-140 \\
\mathrm{ng} / \mathrm{L}\end{array}$ & $1-10 \mathrm{ng} / \mathrm{L}$ & [75] \\
\hline $\begin{array}{l}\text { nonylphenol } \\
\text { octylphenol }\end{array}$ & river water & DLLME & GC-MS & 88-107 & $37-2400 \mathrm{ng} / \mathrm{L}$ & $2-30 \mathrm{ng} / \mathrm{L}$ & [76] \\
\hline \begin{tabular}{|l|} 
octylphenol \\
octylphenol \\
monoethoylate \\
octylphenol \\
diethoxylate \\
nonylphenol \\
nonylphenol \\
monoethoylate \\
nonylphenol \\
diethoxylate
\end{tabular} & $\begin{array}{l}\text { tap water } \\
\text { river water } \\
\text { well water }\end{array}$ & DLLME & $\begin{array}{l}\text { HPLC- } \\
\text { FLD }\end{array}$ & $66-79$ & $\begin{array}{l}<\mathrm{LOQ}-500 \\
\mathrm{ng} / \mathrm{L}\end{array}$ & $\begin{array}{l}\text { 20-100 } \\
\mathrm{ng} / \mathrm{L}\end{array}$ & [78] \\
\hline $\begin{array}{l}\text { bisphenol A } \\
\text { bisphenol B }\end{array}$ & food (fish) & $\begin{array}{l}\text { QuEChERS/ } \\
\text { DLLME }\end{array}$ & GC-MS & $68-104$ & $1-99.9 \mathrm{ng} / \mathrm{g}$ & $\begin{array}{l}0.2-0.4 \\
\mathrm{ng} / \mathrm{g}\end{array}$ & [80] \\
\hline
\end{tabular}

\subsection{Ultrasonic Assisted Extraction (UAE)}

Ultrasonic assisted extraction is an appropriate technique for the extraction of analytes from solid samples (soil, food). Samples with proper solvents or a mixture of solvents as extractants are exposed to ultrasound radiation in an ultrasonic bath or using other devices (probes or sonoreactors). Ultrasonic energy generates a lot of tiny drops in liquid media and causes the mechanical degradation of solids. This effect is defined as cavitation and provides contact between samples and solvents which consequently contribute to the efficient recovery of analytes. The most frequently used appliance for obtaining ultrasonic energy is an ultrasonic bath which enables the simultaneous extraction of several samples. Another possibility is applying a probe which is immersed directly into 
the sample. The major advantage of this technique is the possibility of the extraction of unstable compounds at room temperature. UAE however requires the consumption of large amounts of solvent and further preparation of samples including preconcentration and the purification of extracts.

The efficiency of the extraction depends on various factors, such as the frequency of the ultrasonic wave, temperature, time of process, kind of extracting solvent and sample.

This method of extraction was applied in order to isolate a wide range of contaminants like pesticides, drugs, polycyclic aromatic hydrocarbons, polychlorinated and polybrominated biphenyls, heavy metals mainly from soils and food samples.

Sonication assisted extraction in small columns (SAESC) was used for extraction of bisphenol A, tetrabromobisphenol A (TBBPA) and tetrachlorobisphenol A (TCBPA) from agricultural and industrial soils. After extraction with ethyl acetate and derivatization with N,O-bis (trimethylsilyl) trifluoroacetamide analytes were determined by gas chromatography-mass spectrometry. Recoveries of bisphenols were between $88 \%$ and $108 \%$. Bisphenol A was found in all samples at a concentration level of $0.2 \mathrm{ng} / \mathrm{g}$ to $44.5 \mathrm{ng} / \mathrm{g}$, TBBPA in some samples ranges from 0.3-32.2 ng/g, whereas TCBPA was not detected [55]. The same method with a mixture of water: methanol (30:70) as an extracting solvent was used for the isolation of nonylphenol (NP) and nonylphenol ethoxylates $\left(\mathrm{NPEO}_{\mathrm{x}}\right)$ from spiked environmental solid samples, like soil, sediments, compost and sludge. Enrichment and purification step based on solid phase extraction using C18 column. After combined methods SAESC and SPE extracts were analyzed using high performance liquid chromatography coupled with spectrometric detector. The validated procedure was characterized by high values of recovery of sediment (80-95\%) and significantly lower from compost and sludge samples (26-67\%) [56].

Another procedure with ultrasound radiation was proposed by Fontana et al. Authors presented a simple technique based on ultrasound assisted emulsification microextraction (UAEME) for extraction of bisphenol A from liquid beverage samples (cola, energy drink and tonic water). The analyte in situ was derived from with acetic anhydride and simultaneously isolated and concentrated beforehand by using chloroform as a solvent. Several factors including volume and type of extraction solvent, volume of derivatization agent, $\mathrm{pH}$ of sample, time, temperature and ionic strength were investigated. The resulting procedure showed a satisfactory recovery, above $82 \%$. The BPA concentration in the analyzed canned drink samples was below the detection limit of the proposed method [57]. Canned food samples were analyzed by Gallart-Ayala et al. Authors isolated bisphenol A diglycidyl ether, bisphenol $\mathrm{F}$ diglycidyl ether and their derivatives using the ultrasonic bath and ethyl acetate as an extracting solvent. Recoveries of all compounds were between $70 \%$ and $95 \%$. BADGE $2 \mathrm{H}_{2} \mathrm{O}$, BADGE $\cdot \mathrm{H}_{2} \mathrm{O}$, BADGE $\cdot \mathrm{HCl} \cdot \mathrm{H}_{2} \mathrm{O}$ and $\mathrm{BADGE} \cdot 2 \mathrm{HCl}$ were detected in almost all food samples at a concentration ranging from 0.9-675 ng/g, whereas no BFDGE derivatives were found [32].

Navarro et al. compared two extraction methods: focused ultrasound liquid extraction (FULSE) and microwave assisted extraction. Both techniques were applied for isolation of nonylphenol, octylphenol and $17 \beta$-estradiol from fish. Authors studied also two different techniques used to cleanup the extract. For this purpose SPE with Florosil cartridges and gel permeation chromatography were used. More accurate results were obtained during FULSE-SPE procedure. Analytes of the resulting extract were subsequently derived from N,O-bis(trimethylsilyl)trifluoroacetamide (BSTFA) with 1\% of trimethylchlorosilane (TMCS) and completed by using GC-MS. The recovery of analytes were between $106 \%$ and $126 \%$. Finally the developed method was used to extract alkylphenols and $17 \beta-$ estradiol in the zebrafish homogenate had been exposed to a known amount of target analytes. A concentration of $1.8 \mu \mathrm{g} / \mathrm{g}(363-\mathrm{NP}), 33 \mu \mathrm{g} / \mathrm{g}$ (33-OP) and $0.35 \mu \mathrm{g} / \mathrm{g}$ (E2) were obtained [58].

\subsection{Microwave Assisted Extraction (MAE)}

Microwave assisted extraction is another technique which is used for the isolation of analytes from solid samples. This technique involves the absorption of microwave energy by particles. MAE is applied in order to extract a variety of classes of substances from environmental, biological, geological and metallurgical samples, ashes, food and much more. A crucial parameter which affects the efficiency of the extraction process is the selection of a proper solvent. An applicable solvent should easily dissolve an extractive and have non-zero value of dipole moment which is closely related with the absorption of microwave energy and causes an increase in the temperature of the 
solvent. The efficiency of the extraction by UAE depends heavily on some parameters: temperature, pressure, time of process, kind of sample and microwave power.

Zhang et al. developed a method of extraction by microwave assisted extraction for isolation of Novolac glycidyl ethers (NOGE), bisphenol A diglycidyl ether (BADGE) and its derivatives from canned food samples. This technique was optimized by choosing an extraction solvent, microwave power, irradiation time and temperature. The final procedure was set as follows: $n$-hexane:acetone (50:30) as a extracting solvent, irradiation power was $200 \mathrm{~W}$, temperature was $105^{\circ} \mathrm{C}$ and extraction time was 20 minutes. The Obtained extract was subsequently purified onto PS-DVB SPE column and analytes were determined by HPLC with a fluorescence detector. Recoveries of all compounds were between $70.5 \%$ and $103.5 \%$. Concentration of NODGEs and BADGEs in food samples (fish and meat) were in the range from below of LOD to $173.4 \mathrm{ng} / \mathrm{g}$. Authors also compare MAE with other methods: liquid-liquid extraction and ultrasonic assisted extraction. For all techniques n-hexan was used as solvent. Values of recovery for most analytes were the highest when microwave extraction was applied. This method also required a smaller volume of solvent and resulted in the possibility of processing up to a dozen or more samples simultaneously [59].

The microwave assisted solvent extraction followed by solid phase extraction was applied for the isolation of 4-tert-octylphenol and bisphenol A from liver and muscle tissue from rainbow trout. The MASE was achieved by applying a mixture of dichloromethane:methanol (2:1) and the process was carried out for 25 minutes at $20 \%$ power. The resulting extract was next purified onto Sep-Pak $\mathrm{NH}_{2}$ cartridges. Values of recovery of analytes from spiked liver and muscle tissue determined by LC-MS were between $47-79 \%$ [60].

Other examples of usage of this technique for extraction of bisphenol A, 4-tert-octylphenol, 4nonylphenol and natural or synthetic estrogens from river sediments was presented by Liu et al. Authors investigated various parameters which influenced the efficiency: kind of solvent, time and temperature of extraction. Extraction conditions were as follows: methanol as a solvent, temperature of $110^{\circ} \mathrm{C}$ and 15 minutes of time. The step of cleanup was carried out by a non-deactivated gel column. A validation method was used in order to observe these compounds in real samples. The concentration level of examined contaminants determined by GC-MS were between and below LOD to $12 \mathrm{ng} / \mathrm{g}$ dry mass [61].

\subsection{Accelerated Solvent Extraction (ASE)}

This method is based on the usage of the appropriate chosen solvent and the extraction process is carried out at elevated pressure $(10-15 \mathrm{MPa})$ and temperature $\left(50-200^{\circ} \mathrm{C}\right)$ [83]. The term for "accelerated solvent extraction" is the most commonly used name of this technique and occurs in approximately $80-90 \%$ of the publications. This method has been widespread by Dionex (Dionex Corporation, Sunnyvale, CA, USA) through the introduction of an extractor ASE TM 200 and refers to the trade name of its products. A regards to this technique there are also alternative names: "pressurized fluid extraction" which is applied by the American Chemical Society and US EPA and "pressurized liquid extraction" [84].

During the process solvent is pumped into an extraction vessel containing a sample and then is heated and pressurized. The resulting extract is subsequently transferred to the receiver and finally it is purified or directly determined by instrumental techniques. The usage of the pressurized solvent at an elevated temperature accelerates the extraction of analytes by increasing the solubility of compounds in this solvent. Another reason is for the increase in the kinetic rate of desorption of target analytes from the sample matrix. Moreover a higher temperature decreases the viscosity of a solvent which favours better penetration of matrix particles and disrupts interactions between analytes and matrix.

This method shows several advantages which are: reduce solvent consumption and extraction time, wide range of application (solid and semi-solid samples) and automation of process. Extraction efficiency depends on some parameters such as temperature, pressure, extraction time, type of solvent, the composition of the matrix, the extraction mode (static or dynamic) and the use of modifiers and/or additives (surfactants, complexing agents).

Accelerated solvent extraction was used for isolation of various alkylphenols, alkylphenol ethoxylates, bisphenol A and bisphenol diglycidyl ethers from biosolids and food samples (cereals, meat, powdered milk) [7, 13, 48-53]. 
Pardo et al. developed a method which included extraction by pressurized liquid extraction followed by liquid-liquid partition and purification step by solid phase extraction. Resulting new method was applied for simultaneous isolation of bisphenol diglycidyl ether residues (e.g. BADGE, BADGE $\mathrm{H}_{2} \mathrm{O}$, BADGE· $\mathrm{HCl}, \mathrm{BFDGE})$ from canned food samples. Mixture of hexane-acetone $(4: 1, \mathrm{v} / \mathrm{v})$ was chosen as extraction solvent and optimized conditions of this process were: oven temperature of $100^{\circ} \mathrm{C}, 5$ minutes heat-up time under a pressure of 1500 psi and two static cycles (5 minutes of each stage). Obtained extract were re-extracted with acetonitrile and cleaned-up through C-18 and aminopropyl bonded to silica combined SPE columns and subsequently analysed by LC-MS/MS. Recovery values for all analytes were above $75 \%$ with a quantification limit of $5 \mathrm{ng} / \mathrm{g}$. In none of the samples (various canned fish and baby food) bisphenol derivatives were not detected [7].

Method of pressurized solvent extraction with liquid chromatography-tandem mass spectrometry was also developed for the simultaneous extraction of BPA, octyl- and nonylphenol from powdered milk and infant formulas. Authors checked different solvents or mixtures of them (methanol, dichloromethane, acetone and ethyl acetate). Furthermore various temperatures, number of cycles and matrix dispersant agents were tested to establish which provided the best recoveries. Analytes were isolated using the optimized parameters: ethyl acetate as solvent, temperature of $70^{\circ} \mathrm{C}, \mathrm{C} 18$ as a dispersing agent and three cycles of extraction. These conditions provided a recovery of between 89$101 \%$. Almost all examined samples were contaminated by at least one compound. The concentration was in the range $0.07-1.29 \mathrm{mg} / \mathrm{kg}, 0.028-1.55 \mathrm{mg} / \mathrm{kg}$ and $0.026-1.47$ for BPA, OP and NP, respectively [48]. These compounds were also isolated from meat samples. Parameters which provide appropriate extraction efficiency were evaluated (temperature, solvent, pressure) and the optimal condition were: dichloromethane as solvent, temperature of $100^{\circ} \mathrm{C}$, pressure of 1500 psi and static cycle 3 times. Crude extracts were cleaned-up using amino-propyl solid phase extraction cartridges and afterwards analytes were determined by LC-MS/MS. The recoveries of the compounds from spiked meat samples were in the range of $89-101.3 \%$. Among the various examined samples bisphenol A was found in 13 of 27 samples $(0.33-7.08 \mu \mathrm{g} / \mathrm{kg})$, nonylphenol in 21 samples $(0.49-55.98$ $\mu \mathrm{g} / \mathrm{kg}$ ) and octylphenol only in three samples at a concentration of about $0.1 \mu \mathrm{g} / \mathrm{kg}$ [13]. Also the usage of methanol as an extraction solvent during the PLE process with one static cycle results in satisfactory recovery values of phenolic compounds in the range of $81-104 \%$. A method was applied for the isolation of BPA, NP, 4-tert-butylphenol (4-t-BP), 4-tert-butylbenzioic acid and chlorophenols from corn breakfast cereal samples with the addition of diatomaceous earth as a dispersant agent. Further purification and preconcentration steps involving SPE with Oasis HLB cartridges was necessary. A combination of two techniques PLE-SPE with LC-MS brought successful results and allowed substances from food samples to be examined. Authors also studied the background contamination which can derive from several laboratory devices, such as manual syringes, plastic SPE cartridges and glassware. They observed a trace level of 4-t-BP and BPA which can overestimate the real amount of these compounds present in an analyzed matrix [49].

Accelerated solvent extraction was also used for the extraction of phenolic compounds from environmental solid samples. Kreisselmeir et Dürbeck presented a method for simultaneous isolation and determination of non-ionic surfactants in particular the alkylphenolethoxylate-type, their degradation products, the alkylphenols, and anionic surfactants - linear benzenosulfonates from river sediments. The authors applied a combination of two techniques, ASE and supercritical fluid extraction. Extraction of anionic surfactants and alkylphenols was achieved applying ASE with pure methanol $\left(100^{\circ} \mathrm{C}, 150 \mathrm{~atm}, 5\right.$ minutes), while isolation of alkylphenol ethoxylates was accomplished by SFE with carbon dioxide modified with methanol $\left(100^{\circ} \mathrm{C}, 450 \mathrm{~atm}, 30\right.$ minutes). The obtained recovery values were determined by HPLC with fluorescence detection and were above 65\% [50]. Selective pressurized solvent extraction was also used to isolate BPA, natural and synthetic estrogens from the soil. This process involves PLE combined with in situ purification of the extract by packing into the cell a sample which is dispersed as an adsorbent. Due to the fact that the ascertainment of these analytes was achieved by GC-MS, it meant that a derivatisation process was needed. For this purpose authors used BSTFA with 1\% TMCS. The resulted recoveries of all compounds under optimal parameters (acetone:dichloromethane, 1:3 as extraction solvent, silica as dispersant agent, $60^{\circ} \mathrm{C}, 1500 \mathrm{psi}$, one cycle) were satisfactory and were between $71-118 \%$. A concentration of analytes ranged from below the LOD to $67.3 \mathrm{ng} / \mathrm{g}$ and were detected in all soil samples [52]. 
Pressurized solvent extraction was also used for the isolation of alkylphenols and their ethoxylates from biosolid which was sampled from a wastewater treatment plant. Authors optimized the extraction process by multivariate analysis and experimental design with a central composite design and achieved the following optimal parameters: acetone as extraction solvent, $129^{\circ} \mathrm{C}$ and two cycles for 34 minutes of each. The clean-up step was carried out in glass columns filled with aluminium oxide. The detected concentration of all analytes was between $1.2-1053 \mathrm{mg} / \mathrm{kg}$ [51]. Selective PLE was applied for the simultaneous isolation of BPA and alkylphenols (4-tert-butylphenol, 4-nbutylphenol,4-n-pentylphenol,4-n-hexylphenol, 4-n-heptylphenol, 4-n-octylphenol, 4-tert-octylphenol, 4-n-nonylphenol) from sewage sludge samples. During the development of the method the authors optimized the derivatisation step and extraction variables (extraction solvent, clean-up sorbent, temperature, time). The resulting process was achieved using dichloromethane, Florosil, $130^{\circ} \mathrm{C}, 1$ minute and one cycle. SPLE was also compared with a focused ultrasound solid-liquid extraction with ethyl acetate.

$\mathrm{N}$-(t-butyldimethylsilyl)-N-methyl-trifluoroacetamide (MTBSTFA) and BSTFA were tested as derivatisation agents. Under optimal conditions of pressurized solvent extraction recoveries of analytes were between $81 \%$ and $105 \%$, whereas FULSE recovery values were much lower and were between $36 \%$ and $94 \%$. Therefore SPLE was selected as an efficient method for the extraction and purification of phenolic compounds from sewage sludge samples [54].

This extraction technique with liquid chromatography-tandem mass spectrometry Guo et al. applied for simultaneous determination of bisphenol a, tetrabromobisphenol A and perfluorooctonic acid from small household electronic appliances. Analytes were extracted by toluen: methanol (10:1) under the pressure of $1500 \mathrm{psi}$ and $100^{\circ} \mathrm{C}$ and this method gave satisfactory recovery values ranging from 72 $92 \%$. Finally PLE was successfully used for the extraction of analytes in different parts of electronic products. Detected concentration of BPA, TBBPA and PFOA were between 0.0013-0.0105\%, 0.654$1.58 \%$ and $0.00035-0.0064 \%$, respectively [53].

Accelerated solvent extraction is a powerful tool for the extraction of phenolic compounds from solid samples. It presents a high recovery of values and a low limit of detection, but sometimes requires a purification step which is the basis of the solid phase of extraction or usage in situ which is an appropriate adsorbent during the extraction process.

\subsection{Matrix Solid-Phase Dispersion (MSPD)}

Matrix solid phase extraction is a sample preparation technique which is designed for solid samples such as soil, food or tissue. This method consists of the homogenization of a small amount of sample (about 0.1-5 g) with solid adsorbent (e.g. silica). Further this mixture is placed into empty SPE cartridges or syringes and subsequently analytes are removed using a proper solvent. Depending on the solubility characteristics of analytes, appropriate solvent or sequence of solvents are used to elute compounds of interest. The major advantages of MSPD are low sample and solvent consumption, simplicity, possibility of extraction of analytes and the elimination of matrix interference into a single step.

Pérez et al. compared two methods, matrix solid-phase dispersion and microwave assisted extraction, for simultaneous isolation of alkylphenols and parabens from soil. Extraction and purification in both techniques were obtained in situ using Florosil as an adsorbent. Extracts were derivatized with N,Obis(trimethylsilyl)trifluoroacetamide and analyzed by GC-MS. MSPD which was carried out with silica as a dispersant agent and then a blended soil sample with C18 was transferred to a glass column containing Florosil. Acetonitrile was used for the removal of analytes. The same condition (extraction solvent, purification agent) was used during MAE which was carried out in a column. Both procedures showed a high recovery and good sensitivity and ascertainment of seven parabens and two alkylphenols (NP and OP) in two of the samples, but only MSPD yielded satisfactory results for other samples. Furthermore the matrix solid phase dispersion gave a lower limit of detection than MAE (0.1-0.3 ng/g and 0.4-1.1 ng/g, respectively). Therefore MSPE was used for the isolation of contaminants from soils. Three parabens (methyl- and buthylparaben, izobuthylparaben) were detected in most samples $(0.48-8.04 \mathrm{ng} / \mathrm{g}$ ) and nonylphenol was found in some soils (concentration about $0.45 \mathrm{ng} / \mathrm{g}$ ) [70]. Li et al. used this method along with UPLC-MS for extraction and in order to ascertain bisphenol A and some estrogens, such as 17 $\alpha$-ethinylestradiol, 17 $\beta$-estradiol, estrone, dienestrol and estriol from animal-derived food. For this purpose acetonitrile was checked as an 
extracting solvent and mixture of $\mathrm{C} 18$ and Florosil as a dispersing agent. In several milk and meat samples BPA was detected at concentration of $0.30-1.71 \mu \mathrm{g} / \mathrm{L}$ and the amount of estrogens were between $0.13-1.66 \mu \mathrm{g} / \mathrm{L}$ [71]. The same method with ultra-high performance liquid chromatographymass spectrometry was used by Chen et al. when determining BPA nonyl- and octylphenol and their derivatives and the estrogens from sediment and tissues. Samples were homogenized with C18 as an adsorbent and elution was obtained using aliquots of methanol and acetone. Authors evaluated two techniques in order to purify extracts. Eluents were directly passed following alumina cartridges or purify by on-line two-dimensional liquid chromatography (2-D LC), which consisted of restricted access material pre-column. The first method turned out to be favorable because it reduced the matrix effect better than 2-D LC clean-up. The extraction efficiency of all analytes from sediment, fish and clams was $51-101 \%, 36-109 \%$ and $30-111 \%$, respectively [73].

The presence of bisphenol A, nonyl- and octylphenol in eggs and milk was determined by Shao et all. Authors checked some parameters (dispersant agent, clean-up and eluent solvent) and optimized the procedure with $\mathrm{C} 18$ as a dispersant which was applied for the isolation of compounds of interest. Extracts were purified by amino-propyl solid phase extraction and analytes were subsequently determined by LC-MS/MS. This method showed a satisfactory recovery (82.3-102.5\%). Nonylphenol was detected in most of the milk and egg samples at a concentration level between 0.57-17.6 ng/g, whereas bisphenol A and octylphenol were found only in a few samples $(0.35-10.45 \mathrm{ng} / \mathrm{g}$ and 0.1 0.41 , respectively) [74]. Matrix solid-phase dispersion with sequential clean-up was also used for isolation and to purify alkylphenol ethoxylates and alkylphenols from tissue samples. Separation and quantification of analytes was carried out by HPLC with fluorescence detection. The solid phase dispersion material was $\mathrm{C} 18$, whereas aluminum oxide was applied as an adsorbent for the clean-up step. The elution program with three portions of methanol (each of $5 \mathrm{ml}$ ) and one $10 \mathrm{ml}$ volume of dichloromethane was chosen as an applicable sequence for elution alkylphenols and their ethoxylate derivatives. Recoveries of all compounds from spiked fish and mussel samples were satisfactory and were above $90 \%$ [72].

\subsection{Solid Phase Extraction (SPE)}

Nowadays solid phase extraction is one of the most commonly used methods for the preparation of liquid samples (isolation, purification, enrichment of trace amounts of analytes, desalination). This technique based on adsorption of analytes on a solid sorbent and subsequently eluting them using the appropriately selected solvent or mixture of solvents. It is crucial that interaction between analytes and solid adsorbents should be stronger than that between compounds of interest and matrix. The choice of sorbent depends on physicochemical properties of sample components. Non-polar sorbents, such as silica gel modified different functional groups (ethyl-, octyl-, octadecyl-, phenyl-) are applied for the extraction of non-polar and semi-polar compounds. Magnesium dioxide (Florosil), aluminum oxide (Alumina) and silica gel functionalized with cyanopropyl or diol gropus are intended for isolation of polar analytes, whereas ion exchange materials are used for adsorption of ionic substances. These adsorbents applied in the solid phase extraction occur in various forms. The most frequently used are sorbents placed in glass or polypropylene cartridges. Various types of these materials in certain amounts are located inside the cartridges between two frits. Less commonly used are extraction discs which have a thin layer of adsorbent on the surface of glass or teflon disc. This form allows the high retention of analytes with a high flow rate. Another possibility is using the extraction disc placed inside the cartridge. A recently developed form is using pipette tips with a sorbent. The solid phase adsorbent is positioned inside pipet tips and is held in place by filters. This format is characterized because of the following advantages: faster extraction time, less sample volume, solvent and waste. The last format is 96-Well SPE Plates which is a complex system of cartridges (1 or $2 \mathrm{ml}$ with $3-10 \mathrm{mg}$ of sorbent) placed on the plate. These SPE plates allow the simultaneous extraction of multiple samples and can be used in all type of automated extractors.

Solid phase extraction is carried out in successive stages. First step is conditioning of the sorbent which activates the sorbent prior to the loading of a sample. Particles of sorbent are wetted with the selected chosen solvent. Next step is the loading of the sample. During this process analytes are bound with the stationary phase and subsequently a solid bed is washed to remove interferent compounds. Finally, analytes are eluted with the appropriately selected solvents (or mixture of them) which are applied portion-wise and slowly passed through the sorbent. The obtained extracts are analyzed with various instrumental techniques. 
This method has several advantages, such as the possibility of simultaneous separation and preconcentration of analytes, a wide range of various type of sorbents, ease of automation, ease of online connection with instrumental techniques and reducing the amount of solvent.

\subsubsection{Non-selective Sorbents}

Solid phase extraction can be carried out using two approaches: off-line or on-line. First method is more frequently used, because it does not require specialized and expensive equipment, whereas online SPE gives high recoveries and lower detection limit values.

The off-line procedure was used for the isolation of bisphenol A and tetrabromobisphenol A from environmental water (tap water and wastewater). For this purpose bamboo-activated charcoal as a novel SPE adsorbent was used. The authors checked different parameters, such as type and volume of eluent, sample $\mathrm{pH}$ and flow rate. Under optimal conditions satisfactory retrievals $(80.5-119.8 \%)$ were obtained. Both compounds were detected only in wastewater at a concentration ranging from between $13 \mathrm{ng} / \mathrm{L}$ and $31.9 \mathrm{ng} / \mathrm{L}$ [24]. BPA, octylphenol and nonylphenol were isolated from river water samples by BondElute-PPL cartridge with a high recovery and low limits of detection. Analytes were analyzed by GC-MS after the derivatization step with MSTFA. The concentration of these compounds were 9-76 ng/L, 6-22 ng/L and 68-326 ng/L, respectively [27]. For extraction bisphenol A, phenylphenol, alkylphenolic compounds (octylphenol, nonylphenol and their ethoxylates, nonylphenoxy ethoxy acetic acids) and parabens from surface waters Jonkers et al. applied Oasis HLB cartridges. Authors proposed the following procedure: conditioning with hexane, methyl tert-butyl ether (MTBE)/2-propanol (1:1), methanol and nanopure water, loading the sample and washing by nanopure water. The analytes were subsequently eluted with MTBE/2-propanol (1:1), followed by methanol. Median concentrations were 3.26, 0.99 and $1.5 \mu \mathrm{g} / \mathrm{L}$ for total $\mathrm{A}_{9} \mathrm{PE}_{1-4} \mathrm{C}, \mathrm{A}_{9} \mathrm{PEO}_{1-10}$ and NP, respectively. The level of BPA and phenylphenol were generally above $100 \mathrm{ng} / \mathrm{L}$, whereas OP and the total concentration of paraben were lower, with a median concentration of 0.017 and $0.027 \mu \mathrm{g} / \mathrm{L}$, respectively [28].

This method was applied for the isolation of a wide range of derivatives of BADGE and BFDGE in canned beverage samples. The authors used OASIS HLB cartridges for the extraction of analytes and discovered that only BADGE $\cdot \mathrm{H}_{2} \mathrm{O}$ was present in all canned soft-drink. Other examined compounds were not detected [32]. Solid phase extraction can be also used for isolating substances from food samples. Level of bisphenols A and F in honeys were presented by Inoue et al. For this purpose authors applied GL-Pak PLS-2 cartridges with polystyrene divinyl benzene polymer. The recoveries of BPA and BPF were 95.1-103.6\% and 88.2-106\%, respectively. Bisphenol F was not found in any analyzed honey samples, while BPA was detected in some of them at a concentration not exceeding $33.3 \mathrm{ng} / \mathrm{g}$ [33].

Yuan et al. compared two types of reverse-phase sorbents, ENVI-18 and Sep-Pak Vac C18, for the extraction of five selected phenolic xenoestrogens (3-phenylphenol, 4,4'-biphenyldiol, 6-bromo-2naphthol, 2,4-dichlorophenol, pentachlorophenol). Higher recoveries were obtained for ENVI-18 cartridge and it was selected for isolation analytes from tap water and treated wastewater samples. Phenolic substances were found only in wastewater at a concentration ranging from 50-203 ng/L [29]. Maragou et al. used three SPE sorbents (C18, PS-DVB and hydroxylated PS-DVB) for extraction of BPA from milk samples and compared obtained results. C18 proved to be the most suitable sorbent for isolation of analyte. The concentration of bisphenol A in milk and powdered infant formula samples determined by LC-MS were between and below LOD to $15.2 \mathrm{ng} / \mathrm{g}$ [30].

Automated on-line SPE coupled with LC-MS/MS was applied for simultaneous determination of various bisphenols (BPA, BPB, BPE, BPF, BPS) from canned soft drinks including soda, beer, cola, tea and energy drinks. For the extraction the authors used C-18 column, which was previously conditioned with $\mathrm{MeOH}$ :water (5:95) and the elution step was obtained using a gradient program. Recovery values were between $85 \%$ and $100 \%$ for all the studied compounds. Bisphenol A and bisphenol $F$ were found in some beverage samples at a concentration ranging from $44 \mathrm{ng} / \mathrm{L}$ to 607 ng/L, while BPS, BPE and BPB were not detected [6]. Authors applied the same method with C-18 column also for preconcentration of bisphenol $\mathrm{A}$ and their chlorinated derivatives from water samples (wastewater treatment plant, river water and drinking water treatment plant). BPA was detected in river samples at 101-322 ng/L, whereas chlorinated derivatives were found only in the effluent wastewater of the paper recycling plant at a concentration of between $460 \mathrm{ng} / \mathrm{L}$ and $836 \mathrm{ng} / \mathrm{L} \mathrm{[25].}$ 
Automated solid phase extraction coupled with LC-MS was used in order to determine the various classes of endocrine disrupting compounds (estrogens, pesticides and bisphenol A). In this case authors also applied the C-18 cartridge for extraction and preconcentration of analytes from surface water and groundwater. The amount of these contaminants were determined directly in river water samples and after each treatment stage. Recovery values for most substances from spiked water samples were between $90 \%$ and $119 \%$, apart from bisphenol A (81\%) and diethylstilbestrol (70\%). Levels of BPA in river and groundwater were 65-295 ng/L and from below LOD to $7 \mathrm{ng} / \mathrm{L}$, respectively. The authors also clearly demonstrated that most compounds, including bisphenol A, were removed during the water treatment [26]. Automated SPE with PolarPlus $\mathrm{C}_{8}$ Speedisc was applied by Chen et al. for isolation of a wide range of xenoestrogens (bisphenol A, 4-tert-octylphenol, nonylphenol and its ethoxylates, estrogens) from river water. The recoveries obtained for spiked Milli-Q and river water samples were 53.8-93.1\% and 10.1-91\%, respectively. All analytes, except octylphenol, were found in real river water at concentration levels between and below LOD to 1026 $\mathrm{ng} / \mathrm{L}[73]$.

Solid phase extraction using various kinds of cartridges (Oasis HLB, C18 silica, amino propyl silica, aluminum oxide, Florosil) are often applied for clean-up extracts which were obtained after varied extraction techniques: liquid-liquid extraction [21, 22], Soxhlet extraction [3], pressurized solvent extraction $[7,13,49,51]$, ultrasound assisted extraction [56, 58], microwave assisted extraction [59, 60] and matrix solid phase dispersion [74].

\subsubsection{Molecularly imprinted polymers (MIPs)}

Molecular imprinting is rapidly developing a technology which creates the possibility of obtaining selective sorbents. These materials show an ability to recognize and bind only particles of target analyte or its structural analogues. Molecularly imprinted polymers (MIPs) are a class of materials which are achieved by the imprinting process of specific binding sites inside synthetic highly crosslinked polymers. These artificially generated cavities are formed during co-polymerization of functional monomers and cross-linking agents in the present of target molecules. Synthesis of MIPs is a relatively simple and inexpensive procedure and involves the use of functional monomers, target molecule, cross-linking agents and initiators dissolved in porogenic solvent. This mixture of components are subjected to polymerization which can be initiated by temperature or ultraviolet radiation. The monomers bind to the target molecule for example hydrogen bonds, electrostatic interaction or hydrophobic interactions and form a complexes which are subsequently held in position by cross-linking agents. Finally the removal of imprinted molecules reveals three-dimensional binding sites which are complementary in size, shape and functionality to target the analyte. Depending on the nature of interaction between imprinted molecules and monomers there are three strategies of molecular imprinting: covalent, non-covalent and semi-covalent imprinting. Firstly, during the copolymerization, the target is bound with functional monomers by reversible covalent bonds. The rebinding of analyte is based on the same interaction. Non-covalent imprinting is now the most frequently used technique for MIPs preparation. Imprinting molecules, both, during the synthesis and subsequent re-binding to cavities is achieved by non-covalent interaction. Semi-covalent imprinting is, whereas, a method which combines features of two previous techniques. In this case target molecules are covalently bound with functional monomers during the polymerization process, while the re-binding of an analyte to three-dimensional cavities have only a non-covalent nature.

MIPs show high thermal and chemical stability (resistance of acids, basis, organic solvents). Moreover they also have various other advantages, such as low cost, ease of preparation, long-term storage without a loss of their properties which makes MIPs attractive to many applications.

Molecularly imprinted polymers for phenolic compounds (bisphenols, alkylphenols and their derivatives) are usually obtained by non-covalent imprinting techniques [34-41, 82, 85, 86], while in the literature there are only a few reports about covalent or semi-covalent imprinting [39, 87-89]. The latter two techniques require the use of harsh conditions in order to remove target compounds which consequently can result in the partial degradation of the polymer matrix. By applying the method of non-covalent imprinting, the most frequently used functional monomers are: 4-vinylpyridine [36, 37, 42, 67, 86, 89], much less acrylamide [35] and acids: methacrylic acid, 2-(trifluoromethyl)acrylic acid and itaconic acid [34]. MIPs with a covalent or semi-covalent imprinting approach were obtained only for bisphenol A and were synthetized with bisphenol A dimethacrylate as adduct of target-monomers. 
The most commonly used method for preparation of molecularly imprinted polymers for phenolic compounds is precipitation polymerization. This method offers many advantages, such as the possibility of obtaining microsphere particles with a narrow-ranged size which enables the use of this type of MIPs not only as sorbents in extraction techniques, but also for the separation of analytes in chromatographic techniques. The precipitation method was applied for synthesis of MIP for bisphenol A [38] and nonylphenol as target compounds [40]. Bulk polymerization, although it is relatively simple, it is less often used. In recent years an increase in attention of new polymerization approaches, such as swelling and polymerization methods and techniques help to obtain a thin layer of MIP on the surface of the carrier (e.g. silica particles). Two-step and multi-step swelling and polymerization methods were used for preparation of molecularly imprinted polymers for bisphenol A and various homologues of chlorinated BPA $[82,86]$. Another possibility is carried out on a layer of MIP on the solid carrier. Polymers which obtained these techniques, demonstrated much better access to binding cavities. These type of MIP were synthetized for selective recognition of BPA and tetrabromobisphenol A [41, 43]. In situ polymerization techniques, whereas, found that the application for preparation of block co-polymer of 4-VP and EGDMA for BPA as a target molecule. This polymer was used for the isolation of phenolic compounds by solid phase extraction coupled with high performance liquid chromatography [90].

Molecularly imprinted polymers such as sorbents in solid phase extraction were successfully applied for isolation and preconcentration of phenolic compounds (e.g. BPA, BPF, tetrabromobisphenol A, nonylophenols and their derivatives) from various environmental samples (river water, wastewaters, sewage sludge, sediments, soils), food, biological samples (serum, urine) and cosmetics [35, 36, 4043].

Due to the fact that MIPs are usually prepared at the presence of target analytes as imprinting molecules, its leakage can cause false results and preclude precise and accurately analyses. For the prevention of this phenomenon it is more and more common to use structural analogues of analytes or their stable isotopes [44]. As dummy templates of bisphenol A are applied 3,3',5,5'tetrabromobisphenol A, 4-tert-butylphenol, 4,4'-dihydroksybiphenyl and bisphenol $\mathrm{F}$, while for the preparation of MIP a group of chlorobisphenols are used 4-tert-butylphenol and 2,6-dimethylphenol $[68,86,91,92]$. Sambe et al. used a stable isotope BPA-d16 as imprinting a molecule for preparation of hybrid material RAM-MIP (restricted access material-molecularly imprinted polymer). This material was subsequently applied in column-switching liquid chromatography in order to ascertain BPA, chlorophenols and bromophenols from water samples.

Molecularly imprinted polymers are becoming more and more interesting, mainly as sorbents in the solid phase extraction. Their potential results are due to their high selectivity for target analytes and possibility of simultaneous extraction, preconcentration of compound of interest and the removal of substances which are not a subject of analysis.

\subsection{Liquid Membrane Extraction (LME)}

In order to isolate, enrich and purify analytes from complex liquids or gas samples various membrane techniques are used. Among these methods liquid membranes are increasingly used. Liquid membrane is usually at a liquid organic phase which separates two aqueous phases and is immiscible of them. Analytes which consist of one aqueous phase (donor phase) are transported through the membrane into the acceptor phase. The following types of liquid membranes are used: bulk liquid membrane (BLM), emulsion liquid membrane (ELM) and supported liquid membrane (SLM).

The simplest type of membrane is bulk liquid membrane. In this case it consists of thin layers of organic solvent as the membrane phase separates two aqueous phases. BLM was only applied in preliminary laboratory tests in order to choose a kind of organic solvent, $\mathrm{pH}$ of donor, and acceptor phases, time of extraction, carriers and other parameters which have influence on extraction efficiency. The second type of liquid membrane is emulsion membrane. ELM is a three phase system water / oil / water or, rarely, oil / water / oil and are an emulsion of two immiscible phases dispersed into a third solvent. The organic phase can contain surfactant for stabilizing emulsion. The significant disadvantage of ELM is low stability which is the result of insufficient persistence of emulsion and difficulty of isolation of analytes after the extraction process. The most common applied membrane is a supported liquid membrane. A membrane phase is placed in the pores of thin polymeric film which is the supporter. This type of liquid membrane has two formats: flat sheet or hollow fibre. 
The use of a liquid membrane extraction technique has a number of advantages, among which the most important are: high enrichment factor, various kind of organic solvents as membrane phase, possibility of using carrier or modifier, low amount of solvents and automation of extraction.

Liu et al. described a method of continuous flowing liquid membrane extraction (CFLME) technique which is a combination of two techniques: continuous liquid-liquid extraction and flat sheet supported liquid membrane for isolation of bisphenol A from aqueous samples. The authors optimized some parameters, such as flow rates, membrane solvents, $\mathrm{pH}$ of donor and acceptor phase, salting effect. Under appropriate conditions, using dichloromethane as the membrane phase and $0,1 \mathrm{M} \mathrm{NaOH}$ as acceptor phase over a 200-fold enrichment factor was obtained [45]. This method was subsequently applied for the isolation of BPA from tap water, river water and municipal sewage effluent samples. The recovery values for all spiked real samples were between $76 \%$ and $116 \%$. Bisphenol A was found only in one sample (municipal sewage effluent) at concentration $280 \mathrm{ng} / \mathrm{L}$ [46].

Dâas and Hamdaoui developed extraction methods via emulsion liquid membrane for the isolation of bisphenol A from aqueous samples. Effects of various conditions such as surfactant concentration (Span 80), emulsification time, stirring speed, effect of internal phase concentration and volume ratio of internal phase to membrane phase were precisely investigated. The results clearly showed that the appropriate selection of extraction conditions gave a good stability of ELM and high recovery values $-98 \%$ [47].

\subsection{Dispersive Liquid-Liquid Microextraction (DLLME)}

Dispersive liquid-liquid micro-extraction is a new method which is successfully applied in order to isolate target amounts of xenobiotics, mainly due to the large surface area between extracting solvent and liquid samples containing analytes. This technique is also characterized by other various advantages, such as simplicity, ease of operation, low cost and high recovery value and enrichment factors. The extraction process is carried out in two steps. The first stage involves the injection of extracting and dispersing solvents into aqueous samples containing analytes. During this step extracting solvents is dispersed into sample and compounds of interest are extracted and enriched. Subsequently mixtures are centrifuged. This step allows the collection of sedimentation phase and then the determination of analytes using instrumental techniques.

As extracting solvent is often used in non-polar diluents with high density, whereas water-miscible polar diluents are applied as dispersing solvents. Useful extracting solvents which found application in DLLME are chlorobenzene, carbon tetrachloride and tetrachlorethylene, while dispersing solvents are usually acetone, methanol and acetonitrile. Whether the extraction is efficient depends on a wide range of parameters: kind and volume of extracting and dispersing solvents and time of process.

This method is generally used for the isolation of phenolic compounds from environmental water samples. DLLME for the extraction of 4-tert-octylphenol, 4-octylphenol, nonylphenol, 4-nnonylphenol and bisphenol A from seawater was developed and validated by Salgueiro-González et al. 1-Octanol was chosen as an extracting solvent. The process was carried out without any dispersant agent which simplified the experiment. High recovery values were achieved and ranged from 84$104 \%$ for all compounds. The seawater samples showed the presence of these xenobiotics at levels from below methods of the quantification limit to $0.14 \mu \mathrm{g} / \mathrm{L}$ [75]. A simple method for extraction of NP and OP from aqueous samples using simultaneous derivatization and DLLME was proposed by Luo et al. Firstly a mixture of a dispersant/derivatization catalyst (methanol/pyridine) was added to the aqueous sample and then derivatization reagent/extraction solvent (methyl chloroformate/ chloroform) was rapidly injected. After centrifuging, analytes in the sedimented phase were determined by GC-MS. The authors' opitimized some parameters, such as extraction and dispersant solvent, the amount of derivatization agent, time of derivatization and extraction, $\mathrm{pH}$ and ionic strength. Under the optimal conditions nonylphenol and octylphenol were found at a concentration level of 2.4 and $0.037 \mu \mathrm{g} / \mathrm{L}$, respectively [76]. DLLME combined with a high performance liquid chromatography-UV detection was applied in order to extract bisphenol A from river and tap water samples. The analyte was extracted by chloroform and acetone was used as the disperser solvent. The recovery values of BPA from spiked samples were between 93.4-96.6\%. The samples were not positive for BPA [77]. This technique was also applied for the isolation of alkylphenols and their short-chained ethoxylates from river water. The presence of analytes was determined by HPLC with a fluorescence detector. The authors checked various extracting (chloroform, chlorobenzene, 
tetrachloroethylene, trichloroethylene and carbon tetrachloride) and dispersing solvents (ethanol, acetone and acetonitrile). Finally trichloroethylene and acetone were selected. None of the compounds were found in tap and well water samples, whereas all of them were detected in river water in a concentration of below LOQ from $0.5 \mu \mathrm{g} / \mathrm{L}$ [78]. Eleven alkylphenols were simultaneously extracted by DLLME from pyrolysis solid residues. The optimization of this extraction process involved some parameters: nature and amount of extracting and dispersing agent and salting-out effect. In this case trichloroethylene and acetone were also selected as the most favorable configuration. The recoveries were in the range of $61.9-101.4 \%$ for all compounds, except for o-methylphenol (45.2\%). The detected amount of analytes were between and below LOD to $4239 \mu \mathrm{g} / \mathrm{L}$ [81].

Another possibility was presented by Zhou et al. This new method, named temperature-controlled ionic liquid dispersive liquid-phase microextraction, was used for the isolation of BPA, 4-n-NP and 4tert-OP from real water samples. In this case the authors used 1-octyl-3-methylimizolium hexafluorophosphate as an extraction solvent. A sample mixture $\left(\mathrm{C}_{8} \mathrm{MIM}\right)\left(\mathrm{PF}_{6}\right)$ was heated to dissolve completely the ionic liquid in the aqueous sample and then it was cooled which led to obtaining a cloudy solution. This mixture was subsequently centrifuged and analytes in the sediment phase were determined by HPLC-FLD. Some parameters (volume of ionic liquid, dissolving temperature, time of extraction, $\mathrm{pH}$ of sample and salting effect) were investigated. Recoveries of analytes in spiked river water, wastewater and melted snow water were between $82.8-117 \%$. No BPA and alkylphenols were found in blank samples [79].

Another example is the combined method for simultaneous extraction of bisphenol A and bisphenol B from canned seafood samples. These techniques are based on a liquid-liquid portioning with acetonitrile and salts (QuEChERS) combined with dispersive liquid-liquid microextraction. QuEChERS is a new extraction method developed for food analysis which includes solvent extraction from high-moisture samples with acetonitrile and partitioning with salt (mainly $\mathrm{MgSO}_{4}$ ). The raw extract obtained is purified by dispersive SPE. Due to the low enrichment factor the authors applied DLLME after the QuEChERS step. During the DLLME process tetrachloroethylene was used as an extracting solvent, whereas the acetonitrile extract obtained from QuEChERS was used as a dispersing solvent. Due to the fact that extraction of bisphenol A was achieved by GC-MS, derivatization of analytes was necessary. For this purpose anhydride acetic was used as a derivatizating agent. The authors optimized some factors, such as the kind and amount of QuEChERS reagents (salts and sorbents), amount of extractive and dispersive solvents, and kind and amount of derivatizing amounts. The resulting method showed a high recovery (68-104\%). BPA was detected in most canned fish samples at a concentration level of between $1.0-99.9 \mu \mathrm{g} / \mathrm{kg}$, while bisphenol B was found only in one sample $(21.7 \mu \mathrm{g} / \mathrm{kg})[80]$.

\subsection{Stir-Bar Sorptive Extraction (SBSE)}

Stir-bar sorptive extraction is the new solventless preparation method which is applied for extraction and the enrichment of target amounts of analytes from liquid samples. This technique is based on adsorption of compounds on a stir bar which is covered in a layer of adsorbent material. The adsorption process occurs during extensive stirring and then analytes are thermally desorbed and analyzed mainly by gas chromatography. Nowadays only the Twister stir bar covered in polydimethylsiloxane is available on the market.

Due to the fact that the ascertainment of anayltes was primarily obtained by GC-MS, the derivativisation step is necessary. For this purpose two strategies are used: acetylation with acetic acid anhydride and silylation with N,O-bis (trimethylsilyl) trifluoroacetamide (BSTFA) or N-(tertbutyldimethylsilyl)-N-methyltrifluoroacetamide (MTBSTFA). The first approach aims for derivatives of compounds containing phenolic moieties, whereas the second method can be applied to a wide range of functional groups (aliphatic and aromatic alcohols, carboxylic acids, amines and amides).

A method for extraction and determination of some alkylphenols and bisphenol A by stir bar sorptive extraction with gas chromatography-mass spectrometry was described by Nakamura et Daishima. The process was performed at room temperature for 60 minutes, at $1000 \mathrm{rpm}$ and involved in situ derivatisation with acetic acid anhydride. Recovery values were very satisfactory in the range of 85.3$105.9 \%$. SBSE was applied for the determination of compounds of interest in river water samples. Bisphenol A, 4-tert-octylphenol and nonylphenol were detected at $11.3 \mathrm{ng} / \mathrm{L}, 2.5 \mathrm{ng} / \mathrm{L}$ and $14.9 \mathrm{ng} / \mathrm{L}$, respectively [62]. A similar method with the derivatisation step with acetic acid anhydride was used for isolation of BPA in river water, urine, plasma and saliva samples. After enzymatic deconjugation 
for releasing free BPA in biological samples, the analyte was extracted forthwith from a derivative of the substance. The average recoveries of bisphenol $\mathrm{A}$ in all samples were higher than $95 \%$. This xenoestrogen was detected in river water at concentration levels of $39 \mathrm{pg} / \mathrm{ml}$ and $47 \mathrm{pg} / \mathrm{ml}$. BPA could not be found in either of the urine, plasma and saliva samples before $\beta$-glucoronidase deconjugation. However bisphenol concentration of $220-450 \mathrm{pg} / \mathrm{ml}$ were detected after this process [63]. Iparraguirre et al. optimized some variables (addition of methanol as modifier or an inert salt, temperature, agitation speed and time) for effective extraction of BPA, alkylphenols, estrogens and sterols from estuarine and wastewater samples. Isolation of compounds was carried out at room temperature and $600 \mathrm{rpm}$ for 15 hours and analytes were derivatived in tube by BSTFA. Good recovery values were achieved for most substances (78-124\%). BPA, E1, androsterone, equilin, coprostan-3-ol and cholesterol were found in all samples at concentration levels between 3-608 ng/L [64].

This method combined with ultrasound assisted extraction was applied for simultaneous extraction of alkylphenols and phthalate esters from various food samples. The strategy involved using ultrasonic radiation for extract analytes from a solid food matrix and the subsequently obtained extract was preconcentrated by SBSE. Methanol was used as an extraction solvent during sonication of samples. The optimized procedure gave high recoveries (83-118\%) and found an application for the analysis of both vegetables packed in plastic packaging and cans and corresponding filling liquids of the canned food. Nonylphenol and octylphenol were detected only in one sample (48 ng/g and $2.3 \mathrm{ng} / \mathrm{g}$, respectively), whereas phthalates occurred most frequently in all samples $(0.28-51 \mathrm{ng} / \mathrm{g})$ [65]. A combination of these two methods with in situ acetylation was also applied for extraction of BPA, alkylphenols and chlorophenols from soil and sediment samples. Authors studied different parameters to obtain satisfactory results. Methanol was selected as a solvent during the sonification process and SBSE was carried out at $900 \mathrm{rpm}$ at room temperature for six hours. This procedure was also compared with pressurized solvent extraction and results clearly demonstrate that only UAE-SBSE can detect trace amounts of compounds in soil, whereas some analyte was found in river sediment using also PLE [66].

Several bisphenols (BPA, bisphenol F, bisphenol Z) and biphenol from canned beverages and filling liquids of canned vegetable samples were extracted by SBSE with GC-MS. Authors applied two derivatisation methods: in situ acetylation and in tube silylation and compared results with those obtained when analytes were not derivatized. These procedures were about from 30 to 70 times more sensitive than when determining underivatized compounds. Finally derivatisation was achieved using acetic anhydride. Extraction was carried out at $600 \mathrm{rpm}$ for three hours. Bisphenols were found in most samples at concentration levels in the range of 0.08-13.98 $\mu \mathrm{g} / \mathrm{L}$, while biphenol was detected in only one sample $(0.58 \mu \mathrm{g} / \mathrm{L})[4]$.

A new possibility is the use of molecularly imprinted polymers (MIP) as selective sorbent covered stir bar (details about MIPs are described in Section 3.5.2). This method was applied for isolation of BPA from water and milk samples. Sheng et al. obtained MIP with 4,4'-dihydroxybiphenyl as dummy template, 4-vinylpyridyne as functional monomer and ethylene glycol dimethacrylate as cross-linker. This type of stir bar was used for extraction of bisphenol A from aqueous solution containing BPA, 4tert-buthylphenol, 4,4'-dihydroxybiphenyl and 3,3',5,5'-tetrabromobisphenol A. MIP-coated stir bar showed better selectivity than the bars with polydimethylsiloxane or non-imprinted polymer. Similar results were obtained by Zhan et al. In this case the preparation of MIP tetrabromobisphenol A was used as dummy template molecules. In both references the authors optimized various parameters (extraction time, $\mathrm{pH}$, stirring speed) and obtained high recoveries above 87\%. The detected concentration of bisphenol A in tap water and milk determined by HPLC-FLD were $47.5 \mathrm{ng} / \mathrm{L}$ and $160-360 \mathrm{ng} / \mathrm{L}$, respectively $[67,68]$. Hu et al. proposed using of polydimethylsiloxane/ $\beta$-cyclodextrin (PDMS/ $\beta-\mathrm{CD}$ ) stir bar for effective isolation of bisphenol A from drinking water and in leachate of one-off dishware. This stir bar showed good thermal stability, solvent-resistance and better selectivity for polar compounds than PDMS coated stir bar. High recovery values were obtained and were between $86 \%$ and $116 \%$. BPA was found in almost all samples at concentration levels ranging from $100-470 \mathrm{ng} / \mathrm{L}$ [69].

\section{Conclusion}

There are reasonable concerns, that bisphenols, alkylphenols and their derivatives are endocrine disrupting compounds and may cause adverse effects on the health of living organisms, also humans. Due to the fact, that all these substances exist in various areas of the environment in trace 
concentration and this low level is sufficient to show biological activity there is a need to develop applicable methods for extraction and determination of these phenolic compounds. The complexity of examined samples (environmental water, soils, food, biological fluids) usually requires the application of arduous and time-consuming processes for the isolation and enrichment of analytes and purification of samples. Consequently there are more and more frequently used methods which enable the performance of pretreatment of samples in one stage.

Nowadays definitely the most commonly applied method is solid phase extraction, which gives high recoveries, low values of limit of detection and good selectivity. Other useful methods, such as ultrasound or microwave assisted extraction, pressurized solvent extraction and matrix solid phase dispersion are also often used, but these extraction processes give crude extracts which require a purification step.

Promising techniques are also dispersive liquid-liquid microextraction and liquid membrane extraction, mainly due to the lower consumption of organic solvents. Whereas stir-bar sorptive extraction, despite their potential and simplicity, have one significant drawback - nowadays only Twister stir bars with polydimethylsiloxane are available on the market, which is not selective enough. Liquid-liquid extraction and Soxhlet extraction are rarely applied, because they often give unsatisfactory and unrepeatable results. Scientists constantly search for new and more effective methods which give higher selectivity and a lower limit of detection.

\section{ACKNOWLEDGEMENTS}

Małgorzata Mościpan is a recipient of a Ph.D. scholarship under a project funded by the European Social Fund.

\section{REFERENCES}

[1] http://ec.europa.eu/research/endocrine/background_disruption_en.html.

[2] Hadjmohammadi, M.R. and I. Saeidi, Determination of bisphenol A in Iranian packaged milk by solid-phase extraction and HPLC. Monatshefte fur Chemie, 2010. 141(5): p. 501-506.

[3] Chu, S., G.D. Haffner, and R.J. Letcher, Simultaneous determination of tetrabromobisphenol A, tetrachlorobisphenol A, bisphenol A and other halogenated analogues in sediment and sludge by high performance liquid chromatography-electrospray tandem mass spectrometry. Journal of Chromatography A, 2005. 1097(1-2): p. 25-32.

[4] Cacho, J.I., et al., Stir bar sorptive extraction coupled to gas chromatography-mass spectrometry for the determination of bisphenols in canned beverages and filling liquids of canned vegetables. Journal of Chromatography A, 2012. 1247: p. 146-153.

[5] Jordáková, I., et al., Determination of bisfenol A, bisphenol F, bisphenol A diglycidyl ether and bisphenol $\mathrm{F}$ diglycidyl ether migrated from food cans using gas chromatography-mass spectrometry. Czech Journal of Food Sciences, 2003. 21(3): p. 85-90.

[6] Gallart-Ayala, H., E. Moyano, and M.T. Galceran, Analysis of bisphenols in soft drinks by online solid phase extraction fast liquid chromatography-tandem mass spectrometry. Analytica Chimica Acta, 2011. 683(2): p. 227-233.

[7] Pardo, O., et al., Determination of bisphenol diglycidyl ether residues in canned foods by pressurized liquid extraction and liquid chromatography-tandem mass spectrometry. Journal of Chromatography A, 2006. 1107: p. 70-78.

[8] Erler, C. and J. Novak, Bisphenol A exposure: human risk and health policy. Journal of Pediatric Nursing, 2010. 25(5): p. 400-4007.

[9] Rubin, B.S. and A.M. Soto, Bisphenol A: Perinatal exposure and body weight. Molecular and Cellular Endocrinology, 2009. 304: p. 55-62.

[10] Prins, G., Endocrine disruptors and prostate cancer risk. Endocrine-Related Cancer, 2008. 15: p. 649-656.

[11] Paris, F., et al., Phenylphenols, biphenols, bisphenol-A and 4-tert-octylphenol exhibit $\alpha$ and $\beta$ estrogen activities and antiandrogen activity in reporter cell lines. Molecular and Cellular Endocrinology, 2002. 193: p. 43-49.

[12] Rivas, A., et al., Estrogenic effect of a series of bisphenol analogues on gene and protein expression in MCF-7 breast cancer cells. Journal of Steroid Biochemistry and Molecular Biology, 2002. 82: p. 45-53. 
[13] Shao, B., et al., Analysis of alkylphenol and bisphenol A in meat by accelerated solvent extraction and liquid chromatography with tandem mass spectrometry. Food Chemistry, 2007. 105: p. 1236-1241.

[14] Sole, M., et al., Estrogenicity determination in sewage treatment plants and surface waters from the Catalonian area (NE) Spain. Environmental Science and Technology, 2000. 34: p. 50765083.

[15] Snyder, S., et al., Analytical methods for detection of selected estrogenic compounds in aqueous mixtures. Environmental Science and Technology, 1999. 33: p. 2814-2820.

[16] Dachs, J., D. Van Ry, and S. Eisenreich, Occurence of estrogenic nonylphenols in the urban and coastal atmosphere of the lower Hudson River estuary. Environmental Science and Technology, 1999. 33: p. 2676-2679.

[17] Ademollo, N., et al., Nonylphenol and octylphenol in human breast milk. Environment International, 2008. 34: p. 984-987.

[18] Routledge, E.J. and J.P. Sumpter, Structural features of alkylphenolic chemicals associated with estrogenic activity. The Journal of Biological Chemistry, 1997. 272(6): p. 3280-3288.

[19] Sonnenschein, C. and A. Soto, An updated review of environmental estrogen and androgen mimics and antagonists. The Journal of Steroid Biochemistry and Molecular Biology, 1998. 65(1-6): p. 143-150.

[20] Vílchez, J.L., et al., Determination of trace amounts of bisphenol F, bisphenol A and their diglycidyl ethers in wastewater by gas chromatography-mass spectrometry. Analytica Chimica Acta, 2001. 431: p. 31-40.

[21] Jin, X., et al., Determination of 4-tert-octylphenol, 4-nonylphenol and bisphenol A in surface waters from the Haihe River in Tianjin by gas chromatography-mass spectrometry with selected ion monitoring. Chemosphere, 2004. 56(11): p. 1113-1119.

[22] Sun, C., et al., Single laboratory validation of a method for the determination of Bisphenol A, Bisphenol A diglycidyl ether and its derivatives in canned foods by reversed-phase liquid chromatography. Journal of Chromatography A, 2006. 1129(1): p. 145-148.

[23] Fromme, H., et al., Occurence of phthalates and bisphenol A and F in environment. Water Research, 2002. 36: p. 1429-1438.

[24] Zhao, R.S., X. Wang, and J.P. Yuan, Highly sensitive determination of tetrabromobisphenol A and bisphenol $\mathrm{A}$ in environmental water samples by solid-phase extraction and liquid chromatography-tandem mass spectrometry. Journal of Separation Science, 2010. 33(11): p. 1652-1657.

[25] Gallart-Ayala, H., E. Moyano, and M.T. Galceran, On-line solid phase extraction fast liquid chromatography-tandem mass spectrometry for the analysis of bisphenol A and its chlorinated derivatives in water samples. Journal of Chromatography A, 2010. 1217(21): p. 3511-3518.

[26] Rodriguez-Mozaz, S., M. Lopez de Alda, and D. Barceló, Monitoring of estrogens, pesticides and bisphenol $\mathrm{A}$ in natural waters and drinking water treatment plants by solid-phase extractionliquid chromatography-mass spectrometry. Journal of Chromatography A, 2004. 1045: p. 85-92.

[27] Voutsa, D., et al., Benzotriazoles, alkylphenols and bisphenol A in municipal wastewaters and in the Glatt River, Switzerland. Environmental Science and Pollution Research, 2006. 13(5): p. 333-341.

[28] Jonkers, N., et al., Occurrence and sources of selected phenolic endocrine disruptors in Ria de Aveiro, Portugal. Environmental Science and Pollution Research, 2010. 17(4): p. 834-843.

[29] Yuan, T., et al., Simultaneous Analysis of Five Selected Phenolic Xenoestrogens in Water Sample Using Solid Phase Extraction-Gas Chromatography-Mass Spectrometry. Chromatographia, 2003. 58(9-10): p. 643-648.

[30] Maragou, N., et al., Determination of bisphenol A in milk by solid phase extraction and liquid chromatography-mass spectrometry. Journal of Chromatography A, 2006. 1129: p. 165-173.

[31] Sun, Y., et al., Simultaneous determination of phenolic xenoestrogens by solid-phase extraction and high-performance liquid chromatography with fluorescence detection. Analytical Sciences, 2001. 17(6): p. 697-702. 
[32] Gallart-Ayala, H., E. Moyano, and M.T. Galceran, Fast liquid chromatography-tandem mass spectrometry for the analysis of bisphenol A-diglycidyl ether, bisphenol F-diglycidyl ether and their derivatives in canned food and beverages. Journal of Chromatography A, 2011. 1218(12): p. 1603-1610.

[33] Inoue, K., et al., Contamination of xenoestrogens bisphenol A and bisphenol F in honey: safety assessment and analytical method of these compounds in honey. Journal of Composition and Analysis, 2003. 16: p. 497-506.

[34] Guerreiro, A., et al., Preliminary evaluation of new polymer matrix for solid-phase extraction of nonylphenol from water samples. Analytica Chimica Acta, 2008. 612: p. 99-104.

[35] Wang, Y., et al., A study of the precipitation polymerization of bisphenol A-imprinted polymer microspheres and their application in solid-phase extraction. Polymer Bulletin, 2012. 68(5): p. 1255-1270.

[36] Herrero-Hernández, E., R. Carabias-Martínez, and E. Rodríguez-Gonzalo, Use of a bisphenol-A imprinted polymer as a selective sorbent for the determination of phenols and phenoxyacids in honey by liquid chromatography with diode array and tandem mass spectrometric detection. Analytica Chimica Acta, 2009. 650(2): p. 195-201.

[37] Mei, S., et al., Determination of trace bisphenol A in complex samples using selective molecularly imprinted solid-phase extraction coupled with capillary electrophoresis. Microchemical Journal, 2011. 98: p. 150-155.

[38] Zhang, J., et al., Selective solid phase extraction of bisphenol A using molecularly imprinted polymers and its application to biological and environmental samples. Analytical and Bioanalytical Chemistry, 2006. 385: p. 780-786.

[39] Alexiadou, D., et al., Molecularly imprinted polymers for bisphenol A for HPLC and SPE from water and milk. Journal of Separation Science, 2008. 31: p. 2272-2282.

[40] Núñez, L., et al., Molecularly imprinted polymer for selective extraction of endocrine disrupters nonylphenol and its ethoxylates derivates from environmental solids. Journal of Separation Science, 2008. 31: p. 2492-2499.

[41] Zhu, R., et al., Molecularly imprinted layer-coated silica nanoparticles for selective solid-phase extraction of bisphenol A from chemical cleansing and cosmetics samples. Analytica Chimica Acta, 2010. 658: p. 209-216.

[42] San Vicente, B., F. Navarro Villoslada, and M. Moreno-Bondi, Continuous solid-phase extraction and preconcentration of bisphenol $\mathrm{A}$ in aqueous samples using molecularly imprinted columns. Analytical and Bioanalytical Chemistry, 2004. 380: p. 115-122.

[43] Yin, Y.-M., et al., Dummy molecularly imprinted polymers on silica particles for selective solidphase extraction of tetrabromobisphenol A from water samples. Journal of Chromatography A, 2012. 1220: p. 7-13.

[44] Kawaguchi, M., et al., Molecularly imprinted solid phase extraction using stable isotope labeled compounds as template and liquid chromatography - mass spectrometry for trace analysis of bisphenol A in water samples. Analytica Chimica Acta, 2005. 539: p. 83-89.

[45] Liu, J., et al., Automatic trace-enrichment of bisphenol A by a novel continuous flow liquid membrane extraction technique. Journal of Separation Science, 2001. 24: p. 874-878.

[46] Liu, J., et al., Evaluation of an on-line coupled continuous flow liquid membrane extraction and precolumn system as trace enrichment technique by liquid chromatographic determination of bisphenol A. Talanta, 2003. 60: p. 1155-1161.

[47] Dâas, A. and O. Hamdaoui, Extraction of bisphenol A from aqueous solutions by emulsion liquid membrane. Journal of Membrane Science, 2010. 348: p. 360-368.

[48] Ferrer, E., et al., Simultaneous determination of bisphenol A, octylphenol, and nonylphenol by pressurised liquid extraction and liquid chromatography-tandem mass spectrometry in powdered milk and infant formulas. Food Chemistry, 2011. 126: p. 360-367.

[49] Carabias-Martínez, R., E. Rodríguez-Gonzalo, and P. Revilla-Ruiz, Determination of endocrinedisrupting compounds in cereals by pressurized liquid extraction and liquid chromatographymass spectrometry. Study of background contamination. Journal of Chromatography A, 2006. 1137: p. 207-215. 
[50] Kreisselmeier, A. and H.W. Dürbeck, Determination of alkylphenols, alkylphenolethoxylates and linear alkylbenezenesulfonates in sediments by accelerated solvent extraction and supercritical fluid extraction. Journal of Chromatography A, 1997. 775: p. 187-196.

[51] Maricán, A., I. Ahumada, and P. Richter, Multivariate optimization of pressurized solvent extraction of alkylphenols and alkylphenol ethoxylates from biosolids. Journal of the Brazilian Chemical Society, 2012. 23(2): p. 267-272.

[52] Zhang, Z., et al., Selective pressurized liquid extraction of estrogenic compounds in soil and analysis by gas chromatography-mass spectrometry. Analytica Chimica Acta, 2011. 685: p. 2935 .

[53] Guo, Q., et al., Simultaneous determination of bisphenol A, tetrabromobisphenol A, and perfluorooctanoic acid in small household electronics appliances of "Prohibition on Certain Hazardous Substances in Consumer Products" instruction using ultra-performance liquid chromatography-tandem mass spectrometry with accelerated solvent extraction. Journal of Separation Science, 2013. 36: p. 677-683.

[54] Martínez-Moral, M. and M. Tena, Focused ultrasound solid-liquid extraction and selective pressurised liquid extraction to determine bisphenol A and alkylphenols in sewage sludge by gas chromatography-mass spectrometry. Journal of Separation Science, 2011. 34: p. 2513-2522.

[55] Sánchez-Brunete, C., E. Miguel, and J.L. Tadeo, Determination of tetrabromobisphenol-A, tetrachlorobisphenol-A and bisphenol-A in soil by ultrasonic assisted extraction and gas chromatography-mass spectrometry. Journal of Chromatography A, 2009. 1216(29): p. 54975503.

[56] Núñez, L., E. Turiel, and J.L. Tadeo, Determination of nonylphenol and nonylphenol ethoxylates in environmental solid samples by ultrasonic-assisted extraction and high performance liquid chromatography-fluorescence detection. Journal of Chromatography A, 2007. 1146(2): p. 157163.

[57] Fontana, A., M. Muñoz de Toro, and J. Altamirano, One-step derivatization and preconcentration microextraction technique for determination oh bisphenol $\mathrm{A}$ in beverage samples by gas chromatography-mass spectrometry. Journal of Agricultural and Food Chemistry, 2011. 59: p. 3559-3565.

[58] Navarro, P., et al., Determination of alkylphenols and 17ß-estradiol in fish homogenate. Extraction and clean-up strategies. Journal of Chromatography A, 2010. 1217: p. 5890-5895.

[59] Zhang, H., et al., Microwave-assisted extraction for the simultaneous determination of Novolac glycidyl ethers, bisphenol A diglycidyl ether and its derivatives in canned food using HPLC with fluorescence detection. Journal of Separation Science, 2010. 33: p. 235-243.

[60] Pedersen, S.N. and C. Lindholst, Quantification of the xenoestrogens 4-tert.-octylphenol and bisphenol $\mathrm{A}$ in water and in fish tissue based on microwave assisted extraction, solid-phase extraction and liquid chromatography-mass spectrometry. Journal of Chromatography A, 1999. 864(1): p. 17-24.

[61] Liu, R., J.L. Zhou, and A. Wilding, Microwave-assisted extraction followed by gas chromatography-mass spectrometry for the determination of endocrine disrupting chemicals in river sediments. Journal of Chromatography A, 2004. 1038(1-2): p. 19-26.

[62] Nakamura, S. and S. Daishima, Simultaneous determination of alkylphenols and bisphenol A in river water by stir bar sorptive extraction with in situ acetylation and thermal desorption-gas chromatography-mass spectrometry. Journal of Chromatography A, 2004. 1038: p. 291-294.

[63] Kawaguchi, M., et al., Determination of bisphenol A in river water and body fluid samples by stir bar sorptive extraction with in situ derivatization and thermal desorption-gas chromatography-mass spectrometry. Journal of Chromatography A, 2004. 41-48.

[64] Iparraguirre, A., et al., Optimisation of stir bar sorptive extraction and in-tube derivatisationthermal desorption-gas chromatography-mass spectrometry for the determination of several endocrine disruptor compounds in environmental water samples. Analytical and Bioanalytical Chemistry, 2011. 401(1): p. 339-352.

[65] Cacho, J.I., et al., Determination of alkylphenols and phthalate esters in vegetables and migration studies from their packages by means of stir bar sorptive extraction coupled to gas chromatography-mass spectrometry. Journal of Chromatography A, 2012. 1241: p. 21-27. 
[66] Llorca-Pórcel, J., et al., Analysis of chlorophenols, bisphenol-A, 4-tert-octylphenol and 4nonylphenols in soil by means of ultrasonic solvent extraction and stir bar sorptive extraction with in situ derivatisation. Journal of Chromatography A, 2009. 1216(32): p. 5955-5961.

[67] Zhan, W., et al., Highly selective stir bar coated with dummy molecularly imprinted polymers for trace analysis of bisphenol A in milk. Journal of Separation Science, 2012. 35(8): p. 10361043.

[68] Sheng, N., et al., Dummy molecularly imprinted polymers as the coating of stir bar for sorptive extraction of bisphenol A in tap water. Journal of Separation Science, 2012. 35(5-6): p. 707-712.

[69] Hu, Y., et al., Sol-gel coated polydimethylsiloxane/ $\beta$-cyclodextrin as novel stationary phase for stir bar sorptive extraction and its application to analysis of estrogens and bisphenol A. Journal of Chromatography A, 2007. 1148: p. 16-22.

[70] Pérez, R.A., et al., Determination of parabens and endocrine-disrupting alkylphenols in soil by gas chromatography-mass spectrometry following matrix solid-phase dispersion or in-column microwave-assisted extraction: a comparative study. Analytical and Bioanalytical Chemistry, 2012. 402: p. 2347-2357.

[71] Li, J., et al., Determination of estrogens in animal-derived food by matrix solid-phase extraction couplrd with ultraperformance liquid chromatography-quadruple time of flight mass spectrometry. Analytical Methods, 2013. 5: p. 1004-1009.

[72] Zhao, M., F. van der Wielen, and P. de Voogt, Optimization of a matrix soli-phase dispersion method with sequential clean-up for the determination of alkylphenol ethoxylates in biological tissues. Journal of Chromatography A, 1999. 837: p. 129-138.

[73] Chen, W.L., et al., Ultra-high performance liquid chromatography/tandem mass spectrometry determination of feminizing chemicals in river water, sediment and tissue pretreated using disktype solid-phase extraction and matrix solid-phase dispersion. Talanta, 2012. 89: p. 237-245.

[74] Shao, B., et al., Analysis of alkylphenol and bisphenol A in eggs and milk by matrix solid phase extraction and liquid chromatography with tandem mass spectrometry. Journal of Chromatography B, 2007. 850: p. 412-416.

[75] Salgueiro-González, N., et al., Determination of alkylphenols and bisphenol A in seawater samples by dispersive liquid-liquid microextraction and liquid chromatography tandem mass spectrometry for compliance with environmental quality standards (Directive 2008/105/EC). Journal of Chromatography A, 2012. 1223: p. 1-8.

[76] Luo, S., et al., Determination of octylphenol and nonylphenol in aqueous sample using simultaneous derivatization and dispersive liquid-liquid microextraction followed by gas chromatography-mass spectrometry. Journal of Chromatography A, 2010. 1217: p. 6762-6768.

[77] Rezaee, M., et al., Dispersive liquid-liquid microextraction combined with high-performance liquid chromatography-UV detection as a very simple, rapid and sensitive method for the determination of bisphenol A in water samples. Journal of Chromatography A, 2009. 1216(9): p. 1511-1514.

[78] Zgoła-Grześkowiak, A., Dispersive liquid-liquid microextraction applied to isolation and concentration of alkylphenols and their short-chained ethoxylates in water samples. Journal of Chromatography A, 2010. 1217: p. 1761-1766.

[79] Zhou, Q., Y. Gao, and G. Xie, Determination of bisphenol A, 4-n-nonylphenol, and 4-tertoctylphenol by temperature-controlled ionic liquid dispersive liquid-phase microextraction combined with high performance liquid chromatography-fluorescence detector. Talanta, 2011. 85(3): p. 1598-1602.

[80] Cunha, S.C., et al., Determination of bisphenol A and bisphenol B in canned seafood combining QuEChERS extraction with dispersive liquid-liquid microextraction followed by gas chromatography-mass spectrometry. Analytical and Bioanalytical Chemistry, 2012. 404: p. 2453-2463.

[81] Bernardo, M., et al., Determination of alkylphenols in eluates from pyrolysis solid residues using dispersive liquid-liquid microextraction. Chemosphere, 2010. 79: p. 1026-1032.

[82] Sanbe, H. and J. Haginaka, Uniformly sized molecularly imprinted polymers for bisphenol A and $\beta$-estradiol: retention and molecular recognition properties in hydro-organic mobile phses. Journal of Pharmaceutical and Biomedical Analysis, 2002. 30: p. 1835-1844. 
[83] Sun, H., et al., Application of accelerated solvent extraction in the analysis of organic contaminants, bioactive and nutritional compounds in food and feed. Journal of Chromatography A, 2012. 1237: p. 1-23.

[84] Bjoërklund, E. and T. Nilsson, Pressurised liquid extraction of persistent organic pollutants in environmental analysis. Trends in Analytical Chemistry, 2000. 19(7): p. 434-445.

[85] Jiang, M., et al., Selective molecularly imprinted stationary phases for bisphenol A analysis prepared by modified precipitation polymerization. Journal of Separation Science, 2009. 32: p. 3265-3273.

[86] Kubo, T., et al., Polymer-based adsorption medium prepared using a fragment imprinting technique for homologues of chlorinated bisphenol A produced in the environment. Journal of Chromatography A, 2004. 1029: p. 37-41.

[87] Ikegami, T., et al., Synthetic polymers adsorbing bisphenol A and its analogues prepared by covalent molecular imprinting using bisphenol A dimethacrylate as a template molecule. Analytical and Bioanalytical Chemistry, 2004. 378: p. 1898-1902.

[88] Takeda, K. and T. Kobayashi, Bisphenol A imprinted polymer adsorbents with selective recognition and binding characteristics. Science and Technology of Advanced Materials, 2005. 6: p. 165-171.

[89] Ikegami, T., et al., Bisphenol A - recognition polymers prepared by covalent molecular imprinting. Analytica Chimica Acta, 2004. 504: p. 131-135.

[90] Ou, J., et al., Determination of phenolic compounds in river water with on-line coupling bisphenol A imprinted monolithic precolumn with high performance liquid chromatography. Talanta, 2006. 69: p. 1001-1006.

[91] Watabe, Y., et al., Novel surface modified molecularly imprinted polymer focused on the removal of interference in environmental water samples for chromatografic determination. Journal of Chromatography A, 2005. 1073: p. 363-370.

[92] Kubo, T., et al., On-column concentration of bisphenol A with one-step removal of humic acids in water. Journal of Chromatography A, 2003. 987: p. 389-394. 